\title{
About the influence of materials parameters on the ultimate and fatigue properties of elastomers
}

\author{
L. Chazeau ${ }^{1}$, J.-M. Chenal ${ }^{1}$, C. Gauthier ${ }^{2}$, J.Kallungal ${ }^{1}$ and J. Caillard ${ }^{2}$
}

\begin{abstract}
The aim of this chapter is to revisit the historical works, mechanisms and modeling approaches available in the field of fatigue crack growth resistance and rupture properties. After introducing the methodology developed to evaluate these properties, the impact of testing parameters such as temperature, loading speed and pre-deformation will be highlighted. We will then review the influence of some material characteristics on rupture and crack propagation and the local mechanisms involved. Finally, a theoretical framework primarily dedicated to the description of crack propagation under static load will be discussed, that aims to underline the connection between resistance to crack growth and the ability of a material to dissipate energy.
\end{abstract}

Keywords. Cyclic/static crack growth $\bullet$ Filled polymers $\bullet$ Viscoelasticity $\bullet$ Mullins effect $\bullet$ Rupture properties $\bullet$ Dissipation.

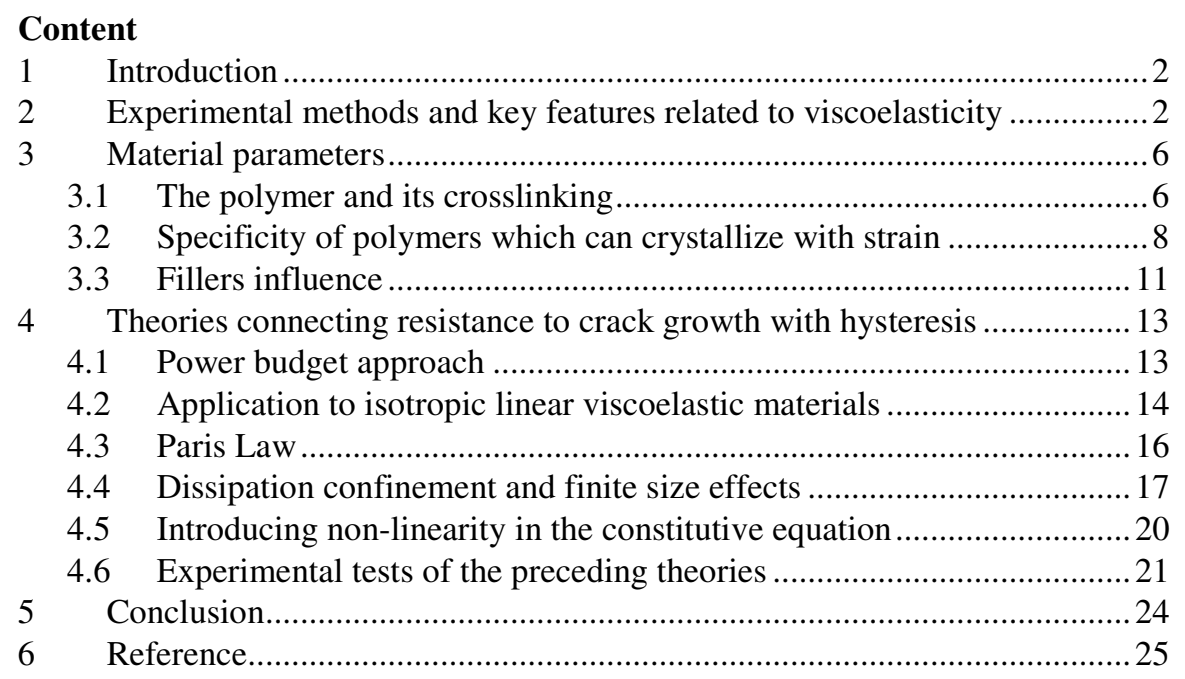

${ }^{1}$ Univ Lyon, INSA Lyon, CNRS, MATEIS UMR5510, F-69621, Lyon, France.

${ }^{2}$ Centre de technologies, Manufacture Française des Pneumatiques Michelin, 63040 Clermont Ferrand Cedex 9, France. 


\section{Introduction}

Optimizing life duration of pneumatics, seismic isolators, mechanical membranes, seals etc. requires a good understanding of the capability of elastomers they are made of, to withstand mechanical loading and resist to crack initiation/propagation. The mechanisms of crack initiation and propagation in elastomers have been of continuous interest to the scientific community, as shown by the numerous reviews on this topic [1-6]. In addition, many recent works have been dedicated to a fine characterization of the material in the close vicinity of cracks. More recently, new fields of applications have emerged in connection with soft robotics, stretchable electronics and bio-medical applications [7]. New ideas for the architecture of biomimetic materials with improved performance ermerged [8, 9]. Recent years have thus seen the synthesis of novel elastomeric networks, such as 'double networks', which appear to provide remarkable fracture properties [10]. This contributed to a renewed interest in understanding and modelling the damage and rupture of elastomeric and filled elastomeric networks [11, 12].

\section{Experimental methods and key features related to viscoelasticity}

From a very general point of view, rupture appears as the consequence of the initiation and eventual propagation of one or more cracks over the entire section of the material. It can occur under a constant, monotonic, or cyclic loading or a combination of these three. Understanding crack mechanisms requires the use of microstructural characterization tools that allow to observe the process of crack appearance from the very beginning. Several studies focused on the links between the processing conditions and the presence of defects, such as cavities, aggregates or agglomerates, from which cracks can nucleate. They are generally extended to the study of the number of cracks created under a given load scenario (monotonic or cyclic). The geometries that allow stress localization and consequently the control of the zone where cracks will appear are generally preferred (e.g diabolo or hourglass type) $[13,14]$, in order to limit the observation region. Many studies use optical or electron microscopy (SEM) to observe the surface of the specimen. The fast development of tomography now allows to access a 3-dimensional information inside the object. This one can be correlated with the strain energy necessary for the crack's nucleation and subsequent propagation that can be calculated at a macroscopic scale or locally through the characterization of strain fields inside the material (using necessarily a modeling step). It is thus possible to better understand the initiation mechanism and its link with local stress or existing flaws in the material (their morphology or their spatial distribution) [15-17]. Nevertheless, note that the 
estimated strain energy, or the local or macroscopic critical stresses / strains to which crack initiation is related, depend very much on observation tools and their resolution.

In many cases, cracks initiation is not considered as the mechanism which dictates the lifetime. Thus, many works have been rather devoted to crack propagation. Different experimental protocols and specimen geometries can be used (the most commonly used geometries are pure shear, trouser, and tensile test-pieces). This can make difficult comparison and generalisation of the results. The test-piece can be strained, at a constant load force and one then measures the crack propagation velocity $\mathrm{Vp}(\mathrm{t})$. The trouser test-piece is the most suitable for this so-called crack growth tests since the stretch of the two legs can be directly related to the crack propagation velocity. Things are less straightforward on notched pure shear (PS) geometry or tensile specimens. In this case, the estimate of the propagation velocity requires a direct measurement of the crack length as a function of time. "Static cut growth test" corresponds to the measurement of the crack propagation velocity after a cut is made in a statically strained PS specimen. In so called "fatigue crack growth tests", the notched test-piece is subjected to a cyclic loading, controlled by deformation or stress, with or without polarization. (i.e. with or without complete unloading).The stabilised propagation rate is then measured per cycle [18] for different loading levels. Such protocols are built to mimic the conditions encountered in numerous applications, where loading levels are relatively low. In these applications, the load frequencies are often signicantly higher than $1 \mathrm{~Hz}$. This can lead to a significant rise in temperature of the material. To avoid it, or at least to limit it, haversine type loading conditions are often used. The term "stabilized" is important: indeed, faster propagation is generally observed during the first cycles, and the crack growth rate decreases more or less rapidly towards a "stabilized" value. This is ascribed to a modification of the crack geometry (initially created from a razor cut), and of the mechanical properties of the material in its vicinity.

Whether static, monotonic or cyclic solicitation are applied, these experiments therefore enable to relate $\mathrm{Vp}$, expressed per time unit (for instance in static crack growth experiment) or per number of cycles (in fatigue crack growth tests) to a strain energy release rate $G$, defined as the variation of potential energy in the specimen per advanced crack area. Note that $G$ is noted $T$ (for tearing energy) in many articles. The resulting $\mathrm{Vp}(\mathrm{G})$ curve is indeed considered to be independent on the geometry [18, 19], at least for those commonly used [20], if certain conditions on the geometries are fulfilled [21]. Using a Pure Shear (PS) geometry, [20, 22, 23] of initial height $\mathrm{h}_{0}$ submitted to a stretching $\lambda, \mathrm{G}$ associated with the propagation of a crack of length $c$, is the product of $W(\lambda)$ by $h_{0}$, where $W(\lambda)$ is the strain energy density of the unnotched PS test piece submitted to the same stretching. For a tensile strip geometry, the expression becomes $2 \mathrm{~kW}(\lambda) \mathrm{c}$, k being a parameter depending smoothly on $\lambda[24,25]$. In the case of an elastic material, $W(\lambda)$ simply is the area under the loading curve of the unnotched test piece, and $\mathrm{G}$ is then the stored elastic energy. The estimate is less trivial for viscoelastic material, or when the mechanical behavior irreversibly depends - over the time scale of the cycles and/or of the crack propagation - on the maximum loading (as it is the case in filled elastomers due to the Mullins effect). In fatigue crack growth test, depending on the authors, 
W(lambda) will then be estimated from the area under the loading curve, or under the unloading one, of a stabilized cycle. Thus, depending on the chosen option, it will include or not the energy dissipated during the cycle (this having important consequences on the interpretation of the $\mathrm{Vp}(\mathrm{G})$ curves) [26].

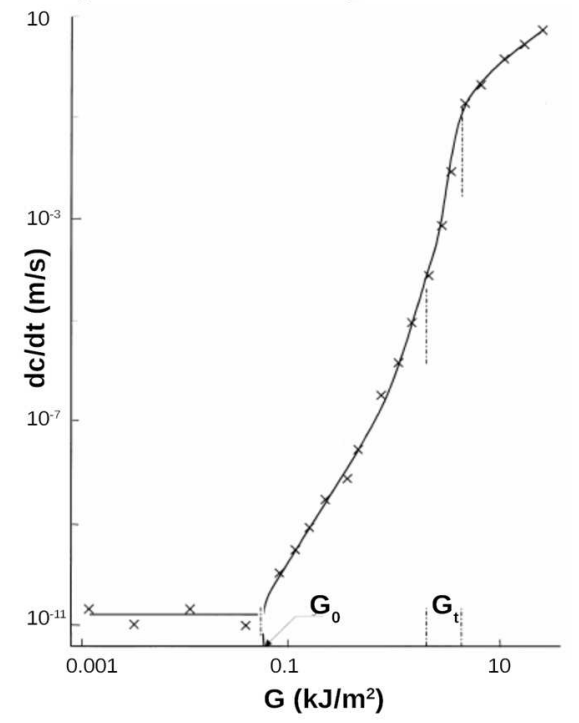

Figure 1 : Crack growth velocity $(\mathrm{dc} / \mathrm{dt})$ as a function of the strain energy release rate $\mathrm{G}$ for Styrene Butadiene Rubber. $\mathrm{G}_{0}$ is the threshold energy for mechanical crack growth and $\mathrm{G}_{\mathrm{t}}$ indicates the transition region. Figure from reference 30 .

There is not a complete consensus in the literature on experimental protocols, whether they are used to assess the properties at break, the tearing resistance or the crack propagation characteristics. However, a generic behavior can be outlined, here introduced in the case of unfilled amorphous elastomers. Their stress and strain at break $\left(\varepsilon_{\mathrm{b}}, \sigma_{\mathrm{b}}\right)$, often measured in tensile test, depend on the strain rate $(\dot{\varepsilon})$ and the temperature. A master curves for $\sigma_{\mathrm{b}}$ (corrected from entropic effects) and for $\varepsilon_{\mathrm{b}}$, can be built, as a function of $1 / \dot{\varepsilon}$ [27], using temperature-dependent shift factors from the William-Landels-Ferry law for the $\alpha$ relaxation times. Furthermore, an envelop curve for the couple $\left(\sigma_{b}, \varepsilon_{b}\right)$ with tests carried out at different speeds and temperatures can be drawn [28]. It highlights the weak rupture properties at high temperature and low velocity, and the existence of optimal temperature and strain rate conditions for the strain energy at break. The latter being related to $G$ via the Greensmith's formula [29], this shows the dependence of the critical strain energy release rate $G_{c}(G$ value for a catastrophic crack propagation) on temperature and strain rate, or in other words, on the role of the viscoelasticity in the involved processes.

$V_{p}(G)$ curves (or the reverse, $G\left(V_{p}\right)$ curves) from non-cyclic crack growth tests are found in literature with crack propagation rates which can extend over ten decades (figure 1)[30]. The authors estimate a tearing energy $G_{t}$ (with a significant error bar), akin to $G_{c}$, when $V p$ reaches several $\mathrm{m} / \mathrm{s}$. In the lower or higher velocity domains, the breaking surfaces are respectively rough and smooth, and the velocity is approximatively or completely stable, while stick-slip occur in the transition domain $[31,32]$. These different behaviors are related to the material ability to blunt 
the crack tip by cavitation [33]. This mechanism involving the viscoelastic response of the material, may or may not have the time to occur, depending on the propagation velocity [34]. The width of the transition domain decreases with the increase in the material crosslinking density. Note that the unstable stick-slip process may also result from a non-uniform temperature in the crack vicinity, that interacts with the local viscoelasticity of the material [26]. Below $\mathrm{G}_{\mathrm{t}}$, two different domains can be distinguished : for $\mathrm{G}$ above a value named $\mathrm{G}_{0}, \mathrm{~V}_{\mathrm{p}}$ roughly varies with a power law of $\mathrm{G}$. Below $\mathrm{G}_{0}$, one observes an extremely low crack propagation rate, independent on $\mathrm{G}$, solely originating from a chemical degradation of the material at the crack tip [35]. $\mathrm{G}\left(\mathrm{V}_{\mathrm{p}}, \mathrm{T}\right)$ data obeys the same time-temperature equivalence as dynamic moduli and makes possible the construction of a master curve over a very large domain. Incidentally, $T$ and $V_{p}$ being given, $G$ grows with the loss modulus. $G_{0}$ has therefore to be estimated when the viscoelastic effects are minimized. The reduction of the dissipation zone can be obtained by pushing an ultra-sharp blade into the open crack. This inspired a new efficient protocol to rapidly evaluate $\mathrm{G}_{0}[36,37]$.Values are found between 20 and $100 \mathrm{~J} / \mathrm{m}^{2}$ [38-42]. According to Lake and Thomas [43], they corresponds to the breaking energy of the chains that cross the fracture plane. When a bond breaks, the entire chain between crosslinks relaxes to zero load, making the energy dissipation proportional to the number of Kuhn segments (N) between crosslinks. Recent studies however suggest that chains rupture out of the fracture plane are also involved in the fracture energy [44] (cf. § 3). Despite its simplifying assumption (perfect network without entanglement), the Lake-Thomas model predicts the right order of magnitude for $\mathrm{G}_{0}$ in unfilled amorphous polymers and the observed dependence of $\mathrm{G}_{0}$ on $\mathrm{N}^{-1 / 2}$. Our study on $\gamma$-irradiated elastomer at different doses suggests that the model also seems to qualitatively work for materials containing a large number of dangling and soluble chains, when these are taken into account in the calculation of $\mathrm{N}$ [45].

Regarding fatigue crack growth tests, the curves are generally given as dc/dn (i.e. the crack growth per cycle) versus G [46]. They have a typical shape, similar to those observed for other classes of materials [47] (figure 2). Like for non cycling loading, three domains are identified. At $\mathrm{G}$ values lower than $\mathrm{G}_{0}$ (same meaning as previously), crack propagation is again ascribed to chemical degradation processes. Then one observes a transition on a restricted domain of $G$, where the $V_{p}(G)$ curve increases, usually according to a linear law. For higher $\mathrm{G}$, dc/dn follows a Paris type law [48], i.e. is equal to $A \cdot G^{\beta}$ where $A$ and $\beta$ are material parameters. Finally, beyond a certain critical value $\mathrm{G}_{\mathrm{c}}$, the crack propagates in a catastrophic way, causing the sample rupture within few cycles.

As shown by Lake and Lindley [49], in the Paris domain $\left(\mathrm{dc} / \mathrm{dn}=\right.$ A. $\left.G^{\beta}\right)$, A decreases rapidly with the frequency increase and then stabilizes for frequencies greater than 10 cycles per minute. At low frequency, crack growth rate evolution can be deduced from the $G\left(V_{p}\right)$ curves obtained in static crack growth tests. For higher ones (above $1 \mathrm{~Hz}$ ), the evolution of A suggests that this term contains a specific contribution due to the cyclic loading. Thus, the link between static and fatigue crack growth becomes more sophisticated, since the frequency both impacts the 
time spent at a given $\mathrm{G}$ and influences the bulk material viscoelastic response. In addition, the use of a positive non-relaxing loading can lead to a slowdown of the crack propagation (by a factor of up to 18 in experiments carried out at $2 \mathrm{~Hz}$ with Styrene Butadiene Rubber). To explain it, Lindley [19] assumed that the dynamic component of $\mathrm{dc} / \mathrm{dn}$ depends on $\left(\mathrm{G}_{\max }-\mathrm{G}_{\min }\right)^{\beta}$, with $\beta$ the exponent of the Paris law obtained in non-relaxing conditions. Note that at low frequency, as the static contribution of $\mathrm{dc} / \mathrm{dn}$ is then preponderant, the increase in $\mathrm{G}_{\min }$ should lead to a larger $\mathrm{dc} / \mathrm{dn}$. The influence of the temperature is more intuitive and similar to that observed in static (A increases with the temperature). Thus, as also deduced from tensile strength measurement, $G_{c}$ decreases with increasing temperature. Note that the quantification of the temperature influence must be carried out so as to ensure that material ageing is avoided (precaution not always described in publications).

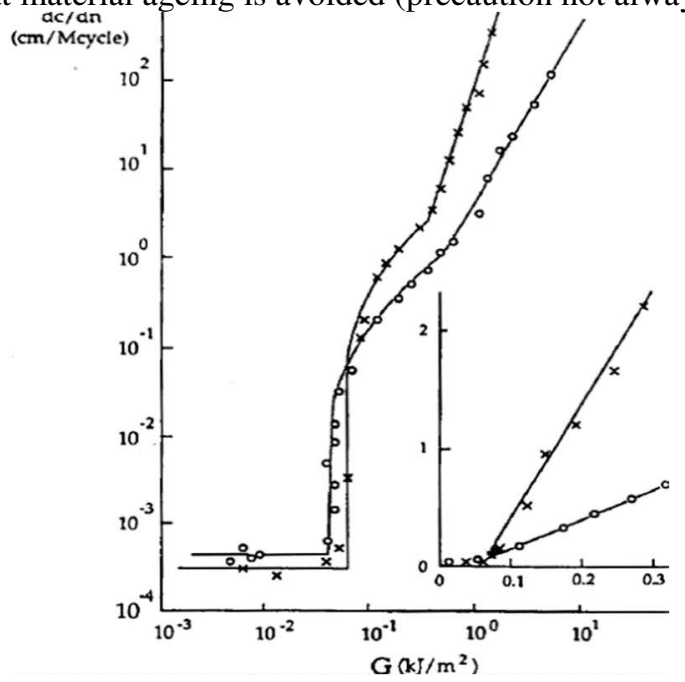

Figure 2: Crack propagation rate as a function of the maximum energy release rate $G$ in fatigue crack growth test for unfilled Styrene Butadiene Rubber (x) and Natural Rubber (o). From reference 6 .

\section{Material parameters}

\subsection{The polymer and its crosslinking}

The strong influence of viscoelasticity in crack propagation can be retrieved in the often used expression of $G$ as the product of $G_{0}$ and a function $f\left(V_{p}, T\right)$ (cf. §4). At a macroscopic scale, the viscoelasticity impacts the evolution of the crack tip geometry during the crack advance and therefore the maximum stresses distribution in its vicinity, which causes its further propagation [36]. At the crack tip locus, for the crack to grow, the subchains immediately ahead have to be stretched enough to reach the breaking strain. Since there is internal viscosity, a force higher than that corresponding to the threshold tearing energy must be supplied. The difference between the strain energy density in the bulk and small energy density used for growth 
of the crack is actually used to overcome the viscosity of the rubber. Viscoelasticity also controls the appearance of other dissipative mechanisms, such as cavitation, fibrillation which may or may not appear in the crack tip and perturb its propagation. Moreover, the chain network density controls $\mathrm{G}_{0}[43]$ and the deformation level at which strain hardening appears, which seems to decrease the radius of the crack tip and increase a stress triaxiality that promotes cavitation [50].

Thus, from a material design point of view, the key parameters for crack propagation resistance are: crosslinking density, entanglement density, the fraction of dangling and free chains, and the glass transition temperature of the polymer. The latter depends on the chemical nature of the polymer chains which also controls the entanglement density (via the chain persistence length), and the energy at break of their bonds. The initial length distribution of the polymer chains controls the presence of chain ends or soluble fraction at a given crosslinking level. The ingredients, the different crosslinking recipes (sulfur, peroxide, disulphide tetramethylthiuram...) and protocols (thermal curing, radiation...) can also be important. Thus, for a same crosslinking density, some authors claim that "conventional" vulcanization system (sulfur / accelerator ratio > 1) leads to better breaking properties and tearing energy (with the Rivlin protocol) than efficient vulcanization system [40]. Interpretations differ on the reasons: more or less spatially homogeneous networks [51], crosslinks formed in a more or less irreversible manner, which may result in more or less built-in/ stresses or strains [52]. Playing with the chemistry of the polymer chains, one can also create physical crosslinks. Their association/dissociation dynamics should enable a redistribution of the stresses in the elastomer network and therefore slow down the crack propagation. Studies are nevertheless necessary to confirm this. Chemical aging has also large consequences on crack resistance, since it induces, through complex chemical processes, additional crosslinks and/or chain scissions [53-56] . The characterization of molar masses between crosslinks remains however a challenge, even if it has recently benefited from advances in $\mathrm{Nu}$ clear Magnetic Resonance [57]. Aging can also be spatially heterogeneous, especially in sulfur vulcanized systems. Characterizing these heterogeneities is also difficult. To sum up, aging and curing conditions can lead to network structures very far from the perfect networks described in most models. This explains apparently contradictory results in the literature [45, 58].

In many cases, the network topology in elastomers results from more or less random crosslinking and/or chain scissions. Nervetheless, better control of this topology is possible.[59] Thus, toughness have been improved with elastomers made of telechelic chains with bimodal length distribution. This improvement comes from a stress redistribution due to the lower extensibility of short chains. The requirements to achieve exceptional toughness seem to be that the components have very different cross-link densities and the morphology is uniform down to the segmental level. With this idea, Buckley et al [60] produced ethylene-propylene double networks with improved rupture properties (at constant modulus). The beneficial effect of multiple networks has also been evidenced in hydrogels [10] and in acrylate elastomers [61] (cf. § 3.4). 


\subsection{Specificity of polymers which can crystallize with strain}

The ability of the polymer for strain induced crystallization (SIC) appears to be another important parameter for crack growth resistance. All elastomers that crystallize with temperature can - under certain strain rate and temperature conditions (near their melting temperature) - crystallize under deformation [62]. Among them, poly-cis isoprene $1,4(\mathrm{NR})$ has two advantages: a melting temperature $\left(35^{\circ} \mathrm{C}\right)$ very close to ambient, and a reversible crystallinity which can reach several tens of $\%$. NR crystallization kinetics [63] is slow, especially at ambient temperature. This explains, with the presence of crosslinking nodes that restrict chain diffusion, that in most cases, NR remains amorphous despite a melting temperature higher than the ambient. When the material is deformed, the chains stretching reduces the system entropy and makes crystallization thermodynamically more favorable. Crystallites can therefore nucleate and grow, for stretch ratio usually above 4, until they reach a size limited by the presence of the crosslinking nodes. This size is small enough for the crystallites to be unstable and melt during unloading, even at room temperature. The NR SIC (and its various parameters) has been the subject of special attention in recent years [64-74] both from an experimental and theoretical point of view. SIC leads to a significant strain hardening, explained by the creation of a network of percolating crystallites within the material (even if questions remain on this topic). It is preceded, at the very beginning of the crystallization phase, by a slight decrease in stress due to the alignment of the crystallized chains portions in the stretching direction (as this decreases the 'effective' stretching of amorphous chains) [75], mostly visible at slow stretching rate.

As shown by the comparison of NR and Styrene Butadiene Rubber (SBR) data [32, 76-78], SIC is the reason for a very strong increase in strain and stress at break and a slower crack propagation velocity, in cyclic and non cycling test[79]. Unlike an amorphous polymer, in a NR Pure Shear specimen submitted to a static loading, after a short growth, the crack stops. In cyclic loading, in the Paris domain, the literature studies suggest an exponent close to 4, for an amorphous elastomer like SBR while it may be around 2 for NR. Note that these exponents can significantly vary, depending on the experimental conditions. In addition, the application of a non-relaxing loading $\left(\mathrm{G}_{\min }>0\right)$ leads to a more important slowing down of the crack propagation than with an amorphous elastomer [25]. Non-relaxing conditions also leads to crack deviations [80] (absent with unfilled amorphous elastomer). That makes less trivial the monitoring of the crack length, which may or may not include secondary cracks. All these behaviors are related to SIC which occurs at the crack tip, even at low macroscopic strain, due to the important stress concentration created by the tip geometry. Several studies investigated cristallinity at the crack tip in NR $[81,82]$. In particular, Rublon et al. $[14,78]$ have implemented a clever method in order to map it during a dynamic test at $0.1 \mathrm{~Hz}$. Directly compared to crack propagation tests performed at $2 \mathrm{~Hz}$ for different energy release rates $\mathrm{G}$, they showed a 
good correlation between $\mathrm{G}$, the crystallized volume, and the thickness decrease at the crack tip, which also suggests that cavitation occurs.

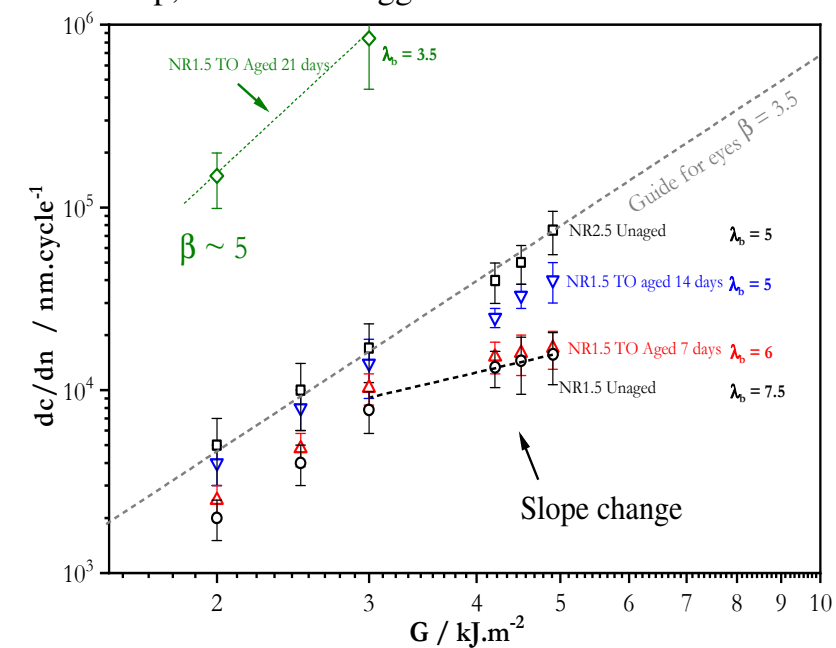

Figure 3: Crack propagation rate as a function of the strain energy release rate $\mathrm{G}$, in fatigue tests, on pure shear sample at $0.01 \mathrm{~Hz}$, for aged and unaged unfilled NR. Tensile stretch at break $\lambda_{b}$ measured in tensile test at $4.2 * 10^{-3} \mathrm{~s}^{-1}$ is also reported. Data from references 83 and 85 .

We have studied a conventionally vulcanized NR (noted NR1.5 on figure 3, with the recipe: $100 \mathrm{phr}$ NR $+3 \mathrm{Phr}$ Sulfur $+6 \mathrm{phrPPD}+2 \mathrm{phr}$ stearic acid $+3 \mathrm{phr}$ CBS + $5 \mathrm{phr} \mathrm{ZnO}$ ). This material has a lower ability to crystallize than an efficiently vulcanized rubber (CBS/Sulfur concentration ratio $<1)$, both during cold crystallization $\left(\right.$ at $-25^{\circ} \mathrm{C}$ ) and during a tensile test experiment, the crystallinity being lowered by a factor of ca. 3. This may be due to a different distribution of the active chain length, and/or the presence of more grafted species on the chains which hinder their crystallization. The fatigue crack growth resistance of the material has been tested in pure shear geometry[83]. As shown in figure 3, in the Paris domain, at low G, the slope of the $\log (\mathrm{G})-\log \left(\mathrm{V}_{\mathrm{p}}\right)$ curve at $0,01 \mathrm{~Hz}$ and at few $\mathrm{Hz}$ (not shown), is surprisingly large, around 3.5 , i.e. close to the slope reported for amorphous materials. A new slope can however be deduced for $G$ values above $3500 \mathrm{~J} / \mathrm{m}^{2}$, which tends to be closer to the value expected for NR (around 2). The crystallization at the crack tip, measured through in-situ experiments $(\mathrm{ZnS}$ has been used as a probe to correctly estimate the material thickness at the crack tip) is reported on figure 4 as a function of $\mathrm{G}$. The slope change in the $\log (\mathrm{G})-\log \left(\mathrm{V}_{\mathrm{p}}\right)$ curve corresponds to the detection of the crystallinity. Interestingly, the maximal measured crystallinity is twice larger than the maximal one measured during tensile test at rupture. As reported in literature $[84,85]$ and as shown by the SAXS images collected during the WAXS measurements [85], cavities develop in the crack tip vicinity. Thus, some amorphous chains are broken and highly stretched fibrils with large crystallinity remain. A careful examination of the crack tip morphology and of the fracture surface may be of interest to confirm this. For unknown reasons, to the best of our knowledge, such studies only exist for fatigued filled NR or for unfilled one in non relaxing condition[80, 86]. Even though fillers likely introduce some differences in crack propagation mechanisms, Xiang et al. conclusion can still be considered. In particular, 
they resume an interesting parallel, initially proposed by Zhou et al. [87], between the mechanisms induced by SIC and those occurring with double networks. At the front of the crack tip, soft domains which might contain cavities, micro-cracks and amorphous or less crystallized rubber parts alternate with hard domains of highly orientated and more crystallized ligaments. The soft domains may act like a damper to absorb energy and thus slow down the crack propagation.

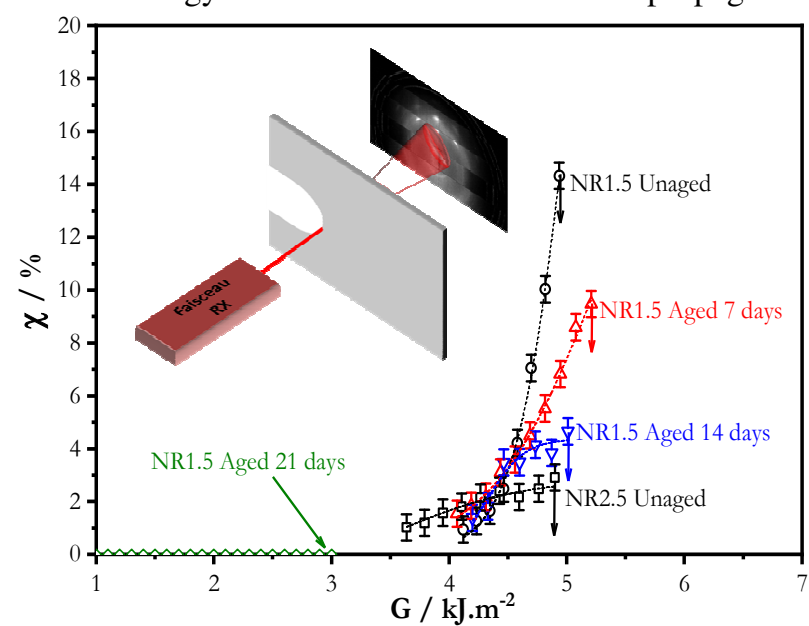

Figure 4: Crystal volume fraction measure by SAXS in situ at the crack tip as a function of the strain energy released rate for aged and unaged NR. Measurements were performed on pure shear specimen at $1.7 * 10^{-3} \mathrm{~s}^{-1}$. Experimental details in references 83 and 85

The close relationship between SIC and crack propagation resistance has also been confirmed with aged NR1.5 samples whose characteristics have been deeply studied by Grasland [88]: ageing in air at $350 \mathrm{~K}$ enhances the heterogeneity of the spatial distribution of the crosslinks already existing in the initial material, and creates highly crosslinked domains which limits the ability for strain induce crystallization. The consequence is an increase in the crack propagation rate (figure 3) which is consistent with a decrease in the crystallinity measured at the crack tip (figure 4). Moreover, the results suggest that a minimum crystallised volume is needed to observe an inflexion on the $\log (G)-\log \left(V_{p}\right)$ curve. This is confirmed by the study of another conventionally vulcanized elastomer, so called NR2.5 (same recipe as NR1.5 except a doubled sulfur content). This material is more crosslinked, and therefore less crystallized than NR1.5 (figure 4). Its crystallization at the crack tip is too low, in the $\mathrm{G}$ domain explored, to lead to any slope change in the $\log (\mathrm{G})$ $\log \left(\mathrm{V}_{\mathrm{p}}\right)$ curve. Moreover, for all these tested materials, the crack propagation resistance at $0,01 \mathrm{~Hz}$ is correlated to the energy and stretch at break, obtained from tensile test at strain rate corresponding to the maximum strain rate in the fatigue test (values reported on figure 3). This is quite expected if one considers that ageing did not change the intrinsic flaw at the origin of the material rupture in tensile test, and therefore that its evolution is mostly related to a change in its crack growth resistance [89].

SIC being a kinetic process [90], in non cyclic experiments, the crack growth velocity in the domain where it is very large (above $0.1 \mathrm{~m} / \mathrm{s}$ ) does not depend on it [30], as SIC does not have the time to proceed. Moreover, concerning fatigue crack 
growth, we have found with the previous NR1.5 material that an increase in frequency by around 3 decades leads to a decrease in dc/dn by a factor 10 (figure 5). However, expressed in $\mathrm{dc} / \mathrm{dt}$ instead of $\mathrm{dc} / \mathrm{dn}$, these data indicates a much faster crack growth which can be ascribed to a less important SIC. This is also suggested by the increase in the $G$ value at which a change in the slope of the $\log (G)-\log \left(V_{p}\right)$ curve is observed (this one being ascribed to a strong increase in crystallinity at the crack tip). In addition, with the NR2.5 material, one observes the decrease in the G value above which there is a fast acceleration of the crack growth rate. In other words, a higher frequency leads to a decrease in the tearing energy of this material, for which strain induced crystallization is so weak that it actually behaves like an amorphous material.

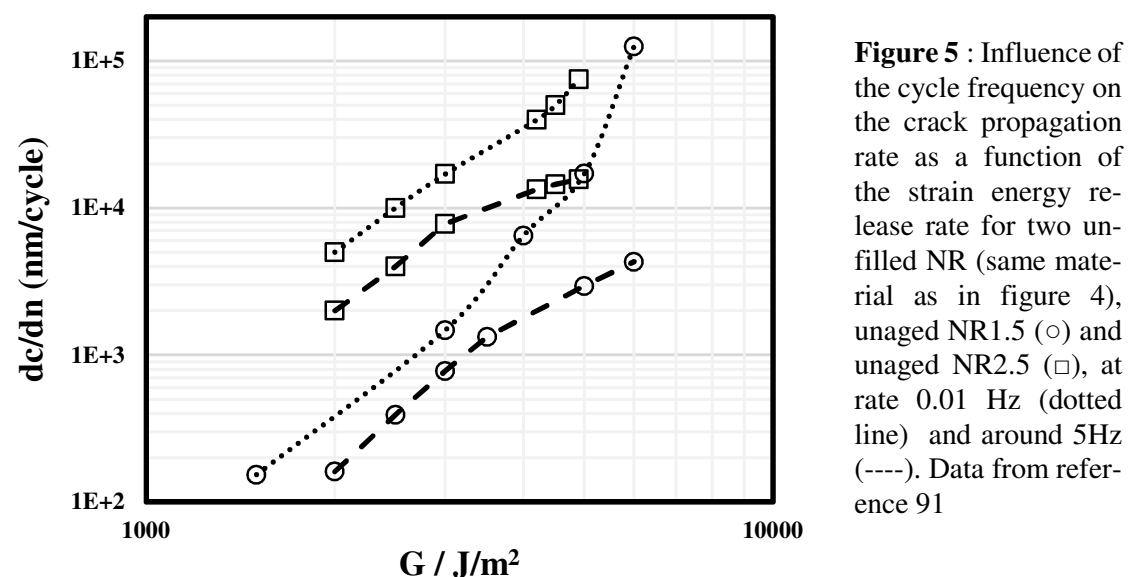

Going back to literature, an increase in temperature has the same consequences on SIC than an increase in frequency. Thus, both can lead to an even greater increase in the crack growth rate than in the case of amorphous elastomers, as they do more than reducing the material viscosity. However, this is dependent on the level of local deformation in the crack vicinity (i.e. on $\mathrm{G}$ ) and, in fatigue, on the local strain rate that will result from the frequency/shape of the macroscopic cycle.

\subsection{Fillers influence}

In most applications, elastomers contain reinforcing fillers. They can be of very diverse natures, the most commonly used in the rubber industry being carbon black or silica nanoparticles. Thus, elastomers are most often nano-composites, with specific viscoelastic properties [91, 92]. An abundant literature has been devoted to their nonlinear viscoelastic properties, so called Payne effect [93]. In addition, they exhibit the so-called Mullins effect, i.e. a progressive modification of the strainstress curve and an hysteresis during the first loading cycle which increases with the increase in the maximum strain [94]. Both Payne and Mullins effects are very 
dependent on the filler content and characteristics (size, aspect ratio, physico-chemical interactions with the polymer). They considerably influence the rupture and crack resistance properties of these materials since they induce additional energy dissipation mechanisms.

Thus, the introduction of rigid nanoparticles is particularly efficient for increasing the tensile strength. Less intuitively, even though they lead to a significant amplification of local deformation in the matrix, nanofillers can also improve the elongation at break (when their content is not too large, i.e. usually below $50 \mathrm{phr}$ ). This is all the more remarkable given that nanofillers can form agglomerates of large sizes acting as crack initiators. Their beneficial effect for crack growth resistance is also observed on various elastomers whether these ones can or cannot crystallize under deformation [3]. The fillers, by amplifying the local strain, enables SIC and therefore a larger crystallized volume at lower macroscopic strain [95]. Nanofillers may also induce larger crystallized volume at a given $\mathrm{G}$, beneficial to fatigue properties [81] (although $\mathrm{G}$ indirectly takes into account strain amplification). A combination of SIC and of reinforcement by nanometric fillers can also lead to tear rotation in tearing test on notched tensile specimen or trouser test-piece [96], not observed without fillers. This enables the relaxation of the local strain (or stress) which is otherwise larger at the crack tip, as shown by a sharper crack tip geometry. Thus, for Medalia [97], tear strength improvement in reinforced elastomer is even mostly associated to tear deviation rather than to energy dissipation (i.e. viscous strengthening or high strain hysteresis). In fatigue tests, more complex crack paths are also observed with fillers, which can lead, in non-relaxing conditions and with crystallizing rubber, to a complete stop of the crack propagation in the direction of the initial cut. Fillers form in the matrix a percolating network (whose connections are potentially ensured by a polymer matrix with modified mobility) which can play the role of a second network. Through decohesion mechanisms and voids formation $[95,98,99]$ in the confined material in between the fillers, this network is gradually destroyed. This leads to the creation of a complex fibrillated structure [100] in which the crosslinked network of the polymer matrix is the last defense against the crack advance [101].

Several filler characteristics (shape, dispersion, polymer/filler interactions) influence the crack growth resistance in a way which depends a lot on the material processing. Bad dispersion may induce stress concentrations and microcracks [102], harmful to rupture properties and crack resistance. The literature indicates a positive influence of larger filler specific surface (i.e. smaller filler size) [79, 103-105] and of higher form factors (like in carbon nanotubes, graphene, graphene oxide or nanoclays) on the resistance to crack initiation and propagation [106, 107]. Combination of nanofillers can also be used to obtain synergistic effect [108], like in the work of Xu et al. [102], who designed a compact hybrid filler network of graphene and MultiWall NanoTubes to toughen NR.

To conclude this paragraph, different mechanisms govern the fracture properties and the propagation of cracks in filled elastomers, and modeling approaches will therefore be essential to allow the evaluation of their respective contributions [5]. 
The next paragraph aims at devising a theoretical framework explaining crack growth and underlining the connection between resistance to crack growth and the ability of a material to dissipate energy. Such theoretical approach can then suggest which bulk material properties should be correlated to crack growth resistance.

\section{Theories connecting resistance to crack growth with hysteresis}

The models that we are reviewed in this paragraph are all built (sometimes implicitly) on the energy budget associated with a propagating crack, and were all devised for static crack growth. To our knowledge, their generalization to cyclic crack growth, which seems possible due to the universality of the energy conservation principle, has not been attempted yet. The theories dedicated to isotropic linear viscoelastic materials are associated with the names of Knauss [38, 109, 110], Christensen [111, 112], De Gennes [113, 114], Hui [115], Persson [116, 117] and their coworkers. More recently, they have been extended outside this range of materials by Long [118], Qi [119] and Zhang [120]. All these theories start from the decomposition $\mathbf{G}=\Gamma_{\text {intrinsic }}+\Gamma_{\text {dissipation with }} \Gamma_{\text {intrinsic }}$ the intrinsic energy required to break molecules at the crack tip (noted $\mathrm{G}_{0}$ in most of the experimental works, $\Gamma_{\text {intrinsic }}$ being tacitly assumed constant) and $\Gamma$ dissipation the portion of $G$ being consumed by the motion of the material surrounding the crack tip as the latter moves ahead ( $\Gamma_{\text {dissipation }}$ is a peculiarity of dissipative materials). These theories aim (sometimes implicitly, as in Knauss and Hui theories) at explaining quantitatively how $\Gamma_{\text {dissipation }}$ can be deduced from the material hysteresis and the loading applied to the specimens.

\subsection{Power budget approach}

The key idea is the recognition that as a crack propagates, the stress singularity accompanying the crack tip [121] translates accordingly, so that any material point in the specimen is successively loaded and unloaded, and the hysteresis associated

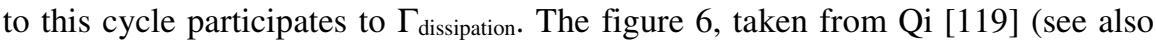
Long [118]) draws explicitly the hysteresis associated with each horizontal "flow line": the closer this line gets to the crack plane, the greater the maximal loading, and therefore the greater the hysteresis.Indeed, by writing in details the energy and entropy budgets of the notched specimen[119], one gets explicitly (Einstein convention of implicit summation over repeated indices being employed)

$$
\begin{array}{r}
\mathrm{G}=\Gamma_{\text {intrinsic }}+2 \int_{0}^{\mathrm{H}_{0}} \int_{-\infty}^{+\infty} \varphi_{\mathrm{p}} \mathrm{dX} d \mathrm{Y} \\
\text { where } \varphi_{\mathrm{p}} \equiv \sigma_{\mathrm{ij}} \frac{\partial \varepsilon_{\mathrm{ij}}}{\partial \mathrm{X}_{\mathrm{p}}}-\frac{\partial \mathrm{W}}{\partial \mathrm{X}_{\mathrm{p}}}=\frac{\partial \mathrm{W}}{\partial \mathrm{X}}-\sigma_{\mathrm{ij}} \frac{\partial \varepsilon_{\mathrm{ij}}}{\partial \mathrm{X}}
\end{array}
$$


Here $2 \mathrm{H}_{0}$ is the specimen height (typically a PS specimen), $\mathrm{X}_{\mathrm{p}}$ is the crack tip abscissa (so that $V_{p}=d X_{p} / d t$ ), $\varphi_{p}$ is the dissipation associated to the crack tip motion divided by $V_{p}$, and finally $\partial / \partial X_{p}=-\partial / \partial X$ since we focus on the stationary regime.

(a)

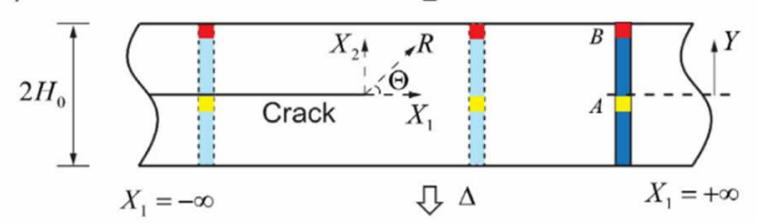

(b)

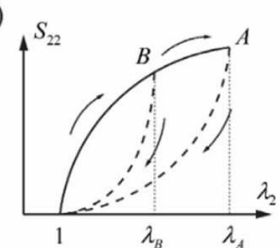

Figure 6 : (a) Two points A and B moving horizontally during steady state crack propagation, shown in the undeformed configuration and in a translating coordinate system centered on the crack tip. (b) Loading histories experienced by points A and B, illustrated by $S_{22}$ versus $\lambda_{2}$ curves. The maximum stress experienced by A is larger due to stress concentration at the crack tip.

Equation (1) can be further simplified by noting that the integral of $\varphi_{\mathrm{p}}$ over $\mathrm{X}$ is the total amount of energy by unit volume dissipated into heat during the matter motion from right to left, that is the mechanical hysteresis associated with this loadingunloading cycle, simply noted "hysteresis". Thus

$$
G=\Gamma_{\text {intrinsic }}+2 \int_{0}^{\mathrm{H}_{0}} \text { hysteresis }(\mathrm{Y}) \mathrm{dY}
$$

It is worth underlining the connection between this approach and the so-called configurational mechanics[122]. Introducing the Eshelby stress tensor $\Sigma_{\mathrm{ij}}=\mathrm{W} \delta_{\mathrm{ij}}$ $-\sigma_{\mathrm{kj}} \partial \mathrm{u}_{\mathrm{k}} / \partial \mathrm{X}_{\mathrm{i}}$, then making use of the mechanical equilibrium $\partial \sigma_{\mathrm{kj}} / \partial \mathrm{X}_{\mathrm{j}}=0$ and of the stress tensor symmetry, one gets

$$
\begin{gathered}
\frac{\partial \Sigma_{1 j}}{\partial X_{j}}=\frac{\partial W}{\partial X_{1}}-\underbrace{\frac{\partial \sigma_{k j}}{\partial X_{j}}}_{=0} \frac{\partial u_{k}}{\partial X_{1}}-\sigma_{k j} \frac{\partial^{2} u_{k}}{\partial X_{j} \partial X_{1}}=\frac{\partial W}{\partial X_{1}}-\sigma_{k j} \frac{\partial}{\partial X_{1}} \frac{1}{2}\left(\frac{\partial u_{k}}{\partial X_{j}}+\frac{\partial u_{j}}{\partial X_{k}}\right) \\
\text { that is } \frac{\partial \Sigma_{1 j}}{\partial X_{j}}=\frac{\partial W}{\partial X}-\sigma_{k j} \frac{\partial \varepsilon_{k j}}{\partial X}=\varphi_{p}
\end{gathered}
$$

In the literature, the contributions to $\partial \Sigma_{1 \mathrm{j}} / \partial \mathrm{X}_{\mathrm{j}}$ of the various internal variables appearing in W are called "local material volume forces", up to a sign. Hence, it is demonstrated that $\Gamma_{\text {dissipation }}$ equals the integral on the whole specimen of these material forces (see also in [5] Horst et al. contribution [123] ). That is, the material forces approach is equivalent to the energy and entropy budgets employed here.

\subsection{Application to isotropic linear viscoelastic materials}

Christensen, De Gennes, Persson and their collaborators applied these budgets to isotropic linear viscoelastic materials. In the sequel we will follow mostly De Gennes intuitive approach.

The material isotropy and linearity imply that the stress field satisfies the same 
equations as in the elastic case. Especially, the dominant term in the stress next to the crack tip is given by the well-known formula plotted above. Hence, if $\mathrm{K}$ is the stress-intensity factor, the amplitude of loading-unloading cycle at vertical coordinate $\mathrm{Y}$ (perpendicularly to crack axis) goes like $\mathbf{K} / \sqrt{ }|\mathbf{Y}|$ and its wave length goes like $|\mathrm{Y}|$, so its pulsation $\omega$ goes like $\mathrm{V}_{\mathbf{p}} / \mathbf{Y} \mid$.

Far from the crack tip, the material remains at equilibrium, i.e. it behaves like an elastic material of Young modulus $E_{0}$. So LEFM theorems apply there. Especially, computing the Rice- or $\mathcal{J}$-integral [121] away from the crack tip gives $\mathrm{G}=\mathcal{J} \propto \mathrm{K}^{2} /$ $\mathrm{E}_{0}$ (this integral must not be confused with compliance $\mathrm{J}$ introduced below).

Next, assume the cycle to be harmonic. If $E^{*}(\omega)=E^{\prime}(\omega)+i E^{\prime}(\omega)$ is the complex Young modulus and $\mathrm{J}^{*}(\omega)=1 / \mathrm{E}^{*}(\omega)$ is the complex compliance, the hysteresis at vertical coordinate $\mathrm{Y}$ reads

$\operatorname{hysteresis}(\mathrm{Y}) \propto \frac{\mathrm{K}^{2}}{|\mathrm{Y}|}\left|J^{\prime \prime}(\omega)\right|=\frac{\mathrm{GE}_{0}}{|\mathrm{Y}|}\left|J^{\prime \prime}(\omega)\right|=\frac{\mathrm{GE}_{0}}{|\mathrm{Y}|} \frac{\mathrm{E}^{\prime \prime}(\omega)}{\left|\mathrm{E}^{*}(\omega)\right|^{2}}$ with $\omega \propto \frac{\mathrm{V}_{\mathrm{p}}}{|\mathrm{Y}|}$ (4). Inserting this relation into equation (2), and noticing that $d Y / Y=d \omega / \omega$, one finally gets

$$
\mathrm{G}=\Gamma_{\text {intrinsic }}+\mathrm{A} \cdot \mathrm{GE}_{0} \int_{0}^{\omega_{\mathrm{c}}} \frac{\mathrm{E}^{\prime \prime}(\omega)}{\left|\mathrm{E}^{*}(\omega)\right|^{2}} \frac{\mathrm{d} \omega}{\omega} \text { with } \omega_{\mathrm{c}}=\mathrm{B} \cdot \frac{\sigma_{\text {rupture }}^{2} \mathrm{~V}_{\mathrm{p}}}{\mathrm{GE}_{0}}
$$

A and B being some undetermined numerical constants. The boundaries of the $\omega$ integral require some explanations. Far from the crack tip, we assumed the material to remain at equilibrium, prompting us to take $\omega_{\min }=0$. Close to the integral, the LEFM fields cannot hold when reaching the zone ahead of the crack tip where the material effectively breaks, the so-called cohesive zone, that is when $|\mathrm{Y}|=\mathrm{Y}_{\text {rupture }}$ such that $\sigma_{\text {rupture }}^{2} \propto \mathrm{K}^{2} / \mathrm{Y}_{\text {rupture, }}$ and we must therefore take $\omega_{\max } \propto \mathrm{V}_{\mathrm{p}} / \mathrm{Y}_{\text {rupture. }}$ Persson set the A coefficient by combining the expected value of the catastrophic tearing energy $\Gamma_{c}\left(G\right.$ limit for infinite $V_{p}$, neglecting inertial effects, also noted $G_{c}$ in experimental work) guessed by De Gennes with a "viscoelastic sum rule" : some examples of such rules are provided by equations (8) and (10) below.

On the one hand, when $\mathrm{V}_{\mathrm{p}}$ grows without limit, the material close to the crack tip should reach its high frequency limit, which is the glassy plateau for the polymers. Thus, it should behave there as an elastic (brittle) material of Young modulus E . Hence computing the $\mathcal{J}$-integral close to the crack tip gives now $\Gamma_{\text {intrinsic }}=\mathcal{J} \propto \mathrm{K}^{2} /$ $\mathrm{E}_{\infty}$, with the same $\mathrm{K}$ since the dominant term in the stress field has a unique expression. Combining this relation for $\mathrm{K}$ with the preceding one, applicable in full generality, one gets

$$
G \rightarrow \Gamma_{c}=\Gamma_{\text {intrinsic }} \frac{E_{\infty}}{E_{0}} \text { when } V_{p} \rightarrow+\infty \quad(6) .
$$

The constant A appearing in (5) must be chosen so that (5) reduces to (6) for "infinite" crack growth rate.

On the other hand, if the material can be represented by a set of Kelvin solids (a spring in parallel to a damper) in series, the complex compliance reads 


$$
J^{*}(\omega)=\frac{1}{E_{\infty}}+\int_{0}^{+\infty} \frac{k(\tau)}{1+i \omega \tau} d \tau=\frac{1}{E_{\infty}}+\int_{0}^{+\infty} \frac{(1-i \omega \tau)}{1+(\omega \tau)^{2}} k(\tau) d \tau
$$

$\mathrm{k}(\tau) \mathrm{d} \tau$ is the equilibrium stiffness of the Kelvin solid of time constant $\tau$. Some elementary manipulations of this decomposition provide

$$
\begin{gathered}
\frac{1}{\mathrm{E}_{0}}=\mathrm{J}^{*}(\omega=0)=\frac{1}{\mathrm{E}_{\infty}}+\int_{0}^{+\infty} \mathrm{k}(\tau) \mathrm{d} \tau \\
\text { and thus } \int_{0}^{+\infty}\left|J^{\prime \prime}(\omega)\right| \frac{\mathrm{d} \omega}{\omega}=\frac{\pi}{2} \int_{0}^{+\infty} \mathrm{k}(\tau) \mathrm{d} \tau=\frac{\pi}{2}\left(\frac{1}{\mathrm{E}_{0}}-\frac{1}{\mathrm{E}_{\infty}}\right)
\end{gathered}
$$

This latter equation is the sum rule we needed. Indeed, making $\omega_{c}=+\infty$ in (5) and reporting the sum rule into it, (6) will be recovered provided we choose $A=2 / \pi$. Hence the final formula

$$
G=\Gamma_{\text {intrinsic }}+\frac{2}{\pi} G_{0} \int_{0}^{\omega_{c}} \frac{E^{\prime \prime}(\omega)}{\left|E^{*}(\omega)\right|^{2}} \frac{d \omega}{\omega} \text { with } \omega_{c}=B \frac{\sigma_{\text {rupture }}^{2} V_{p}}{G_{0}}
$$

$\omega_{\mathrm{c}}$ can be rewritten $\omega_{\mathrm{c}}=2 \mathrm{~B} \mathrm{~W}_{\text {rupture }} \mathrm{V}_{\mathrm{p}} / \mathrm{G}$ where by introducing an "equilibrium" energy of rupture $\mathrm{W}_{\text {rupture }} \equiv 1 / 2 \sigma_{\text {rupture }}{ }^{2} / \mathrm{E}_{0}$ (the "equilibrium" adjective underlines the presence of $\mathrm{E}_{0}$ in this expression). However, keep in mind that this $\mathrm{W}_{\text {rupture }}$ can, like $\sigma_{\text {rupture, }}$ vary with the local temperature and strain rates at the crack tip.

The more sophisticated computations in Persson[116, 117] produced an extra $\sqrt{1-\frac{\omega^{2}}{\omega_{c}^{2}}}$ factor inside the integral, with little impact on the final theoretical predictions.

\subsection{Paris Law}

As noted by De Gennes for a specific rheological model (a so-called Zener solid) $[113,114]$, and later by Persson in greater generality [116, 117], this theory predicts the occurrence of a Paris law, in agreement with experiments. (Strictly speaking, the Paris law originates from cyclic crack growth experiments; here, we use this terminology as a shorthand for " $\mathrm{V}_{\mathrm{p}}$ proportional to some power of G"; as seen in the preceding chapters, such law can also be encountered experimentally in static crack growth.) This is best seen by making use of an approximate sum rule :

$$
\begin{gathered}
J^{\prime}\left(\omega_{2}\right)-J^{\prime}\left(\omega_{1}\right)=\int_{0}^{+\infty}\left(\frac{1}{1+\left(\omega_{2} \tau\right)^{2}}-\frac{1}{1+\left(\omega_{1} \tau\right)^{2}}\right) \mathrm{k}(\tau) \mathrm{d} \tau \approx \int_{1 / \omega_{1}}^{1 / \omega_{2}} \mathrm{k}(\tau) \mathrm{d} \tau \\
\frac{2}{\pi} \int_{\omega_{1}}^{\omega_{2}}\left|J^{\prime \prime}(\omega)\right| \frac{\mathrm{d} \omega}{\omega}=\frac{2}{\pi} \int_{0}^{+\infty}\left[\tan ^{-1}\left(\omega_{2} \tau\right)-\tan ^{-1}\left(\omega_{1} \tau\right)\right] \mathrm{k}(\tau) \mathrm{d} \tau \approx \int_{1 / \omega_{2}}^{1 / \omega_{1}} \mathrm{k}(\tau) \mathrm{d} \tau \\
\Rightarrow \frac{2}{\pi} \int_{\omega_{1}}^{\omega_{2}}\left|J^{\prime \prime}(\omega)\right| \frac{\mathrm{d} \omega}{\omega} \approx J^{\prime}\left(\omega_{1}\right)-J^{\prime}\left(\omega_{2}\right) \approx \frac{1}{\mathrm{E}^{\prime}\left(\omega_{1}\right)}-\frac{1}{\mathrm{E}^{\prime}\left(\omega_{2}\right)}
\end{gathered}
$$

The first line was obtained by assuming $1 /\left(1+\mathrm{x}^{2}\right) \approx \mathcal{H}(1-\mathrm{x})$ for $\mathrm{x} \geq 0$ where $\mathcal{H}$ is the Heaviside step function. The second line used a similar trick, namely $(2 / \pi) \tan ^{-}$ 
${ }^{1}(\mathrm{x}) \approx \mathcal{H}(\mathrm{x}-1)$ for $\mathrm{x} \geq 0$. The last approximation on the third line is more questionable. Reporting (10) into (9), one finally gets

$$
\begin{gathered}
\frac{\mathrm{G}}{\Gamma_{\text {intrinsic }}} \approx \frac{\mathrm{E}^{\prime}\left(\omega_{\mathrm{c}}\right)}{\mathrm{E}_{0}} \\
\text { and thus } \mathrm{E}^{\prime}(\omega) \approx \mathrm{E}_{1}\left(\frac{\omega}{\omega_{1}}\right)^{\alpha} \Rightarrow \mathrm{V}_{\mathrm{p}} \approx \frac{\omega_{1} \mathrm{G}}{2 \mathrm{BW}_{\text {rupture }}}\left(\frac{\mathrm{E}_{0}}{\mathrm{E}_{1}} \frac{\mathrm{G}}{\Gamma_{\text {intrinsic }}}\right)^{1 / \alpha}
\end{gathered}
$$

Hence the Paris exponent $\beta$ equals $\beta=1+1 / \alpha$. For $\alpha=0.5$ (typical of Rouse dynamics), $\beta=3$; and for $\alpha=0.4, \beta=3.5$ : as noted by Persson, these values are typical of SBR in both static and cyclic crack growth. Note also that the approximation on the first line of equation (11) yields the same $\Gamma_{\mathrm{c}}$ expression as the equation from which it is derived. Gent $[124,125]$ proposed on purely phenomenological grounds an equation similar to (11) to fit the results of his peeling experiments : we thus provide here a justification of his intuition. However, Gent used $\omega_{\mathrm{c}}=\mathrm{V}_{\mathrm{p}} / \mathrm{d}$ with $\mathrm{d}$ some material constant, which should be contrasted with our d proportional to G. Actually, (11) brings theory closer to experiments as will be shown below!

\subsection{Dissipation confinement and finite size effects}

The theories developed by Knauss [38, 109, 110] and Hui [115] do not use explicitly the energy and entropy budgets. Rather, they carefully write the mechanical equilibrium of the cohesive zone, using exact results in LEFM (Kolosov-Mushkelishvili formulae and Westergaard functions applied to localized forces along crack lips). In this respect, they provide a more rigorous treatment of the problem. Yet, they yield essentially the same results: same shape for $V_{p}(G)$ curves, same expression for $\Gamma_{\mathrm{c}}$ (apart for one of the four theories studied in Knauss [109, 110]), etc. This is presumably so because energy and entropy conservation remains necessarily in the background.

For instance, Hui and his coworkers demonstrate graphically [115] that the dissipation is confined to the corona $0.05 V_{p} \tau_{r}<$ radius $<3.5 V_{p} \tau_{r}$ where $\tau_{r}$ is the retardation time occurring in the creep compliance (the authors employ a Zener model) and the radius is counted from the crack tip : this region has a negligible area at low $\mathrm{V}_{\mathrm{p}}$ and grows in size with $\mathrm{V}_{\mathrm{p}}$, until becoming eventually macroscopic. This explains qualitatively the trend of our $\Gamma_{\text {dissipation }}$ (recall that the $\mathrm{r} d r \mathrm{~d} \theta$ surface element compensates the decrease of energy like $1 / \mathrm{r}$ ). This discussion makes also clear that the size of the specimen will impact the crack growth curves when $V_{p}$ $\tau_{\mathrm{r}}$ becomes comparable to it. Indeed, so far we have ignored finite size effects, the discussion focusing on "infinite specimens". But finite size effects can be encountered experimentally, in which case the experimental results are not characteristics of the material alone. They are treated in De Gennes [113, 114], who was chiefly 
interested in peeling tests [126]. We will review quickly this treatment, using however a slightly more general constitutive law (see e.g. [127]§ 5.5 pp. 188-226) :

$$
\mathrm{E}^{*}(\omega)=\mathrm{E}_{0}+\left(\mathrm{E}_{\infty}-\mathrm{E}_{0}\right) \frac{(\mathrm{i} \omega \tau)^{\alpha}}{1+(\mathrm{i} \omega \tau)^{\alpha}} \text { (12). }
$$

In the original articles, $\alpha=1$, but we expect $\alpha<1$ for a glass transition. This model has three remarkable limits : soft solid at low frequencies, hard solid at high frequencies, liquid-like behavior in between. From now on, $\mathbf{m} \equiv \mathbf{E}_{\infty} / \mathbf{E}_{\mathbf{0}}>\mathbf{1}$ and we reason exclusively in scaling terms, so that "=" will often stand for " $\propto$ ". The computation of the $G\left(V_{p}\right)$ relation is based on the following principles.

\begin{tabular}{lccc}
\multicolumn{1}{c}{ Approximation } & Soft solid & Liquid & Hard solid \\
\hline Constitutive law & $\sigma=\mathrm{E}_{0} \varepsilon$ & $\sigma=\left(\mathrm{E}_{\infty}-\mathrm{E}_{0}\right)(\omega \tau)^{\alpha} \varepsilon$ & $\sigma=\mathrm{E}_{\infty} \varepsilon$ \\
\hline Pulsation interval & $\omega \tau<\mathrm{m}^{-1 / \alpha}$ & $\mathrm{m}^{-1 / \alpha}<\omega \tau<1$ & $1<\omega \tau$ \\
\hline Spatial domain & $\mathrm{r}_{\mathrm{s}} \equiv \mathrm{m}^{1 / \alpha} \mathrm{V}_{\mathrm{p}} \tau<\mathrm{r}$ & $\mathrm{V}_{\mathrm{p}} \tau<\mathrm{r}<\mathrm{m}^{1 / \alpha} \mathrm{V}_{\mathrm{p}} \tau$ & $\mathrm{r}<\mathrm{V}_{\mathrm{p}} \tau \equiv \mathrm{r}_{\mathrm{h}}$ \\
\hline Stress & $\sigma=\frac{\mathrm{K}}{\sqrt{\mathrm{r}}}$ & $\sigma=\frac{\mathrm{K}}{\sqrt{\mathrm{r}}}$ & $\sigma=\frac{\mathrm{K}}{\sqrt{\mathrm{r}}}$ \\
\hline Displacement & $\mathrm{u}=\frac{\mathrm{K} \sqrt{\mathrm{r}}}{\mathrm{E}_{0}}$ & $\mathrm{u}=\frac{\mathrm{K} \sqrt{\mathrm{r}}}{\mathrm{E}_{\infty}}\left(\frac{\mathrm{r}}{\mathrm{V}_{\mathrm{p}} \tau}\right)^{\alpha}$ & $\mathrm{u}=\frac{\mathrm{K} \sqrt{\mathrm{r}}}{\mathrm{E}_{\infty}}$ \\
\hline Glocal & $\mathrm{G}_{\text {local }}=\frac{\mathrm{K}^{2}}{\mathrm{E}_{0}}$ & $\mathrm{G}_{\text {local }}=\frac{\mathrm{K}^{2}}{\mathrm{E}_{\infty}}\left(\frac{\mathrm{r}}{\mathrm{V}_{\mathrm{p} \tau} \tau}\right)^{\alpha}$ & $\mathrm{G}_{\text {local }}=\frac{\mathrm{K}^{2}}{\mathrm{E}_{\infty}}$ \\
\hline L defining condition & $\frac{\sigma_{\mathrm{p}}}{\delta}=\frac{\mathrm{E}_{0}}{\mathrm{~L}}$ & $\frac{\sigma_{\mathrm{p}}}{\delta}=\frac{\mathrm{E}_{\infty}}{\mathrm{L}}\left(\frac{\mathrm{V}_{\mathrm{p}} \tau}{\mathrm{L}}\right)^{\alpha}$ & $\frac{\sigma_{\mathrm{p}}}{\delta}=\frac{\mathrm{E}_{\infty}}{\mathrm{L}}$ \\
\hline Cohesive length & $\mathrm{L}=\frac{\mathrm{E}_{0} \delta}{\sigma_{\mathrm{p}}} \equiv \mathrm{L}_{0}$ & $\mathrm{~L}=\mathrm{L}_{\infty} \frac{1}{\alpha+1}\left(\mathrm{~V}_{\mathrm{p}} \tau\right)^{\frac{\alpha}{\alpha+1}}$ & $\mathrm{~L}=\frac{\mathrm{E}_{\infty} \delta}{\sigma_{\mathrm{p}}}=$ \\
\hline $\mathrm{V}_{\mathrm{p}}$ range & $\mathrm{V}_{\mathrm{p}} \tau<\mathrm{m}^{-1 / \alpha} \mathrm{L}_{0}$ & $\mathrm{~m}^{-1 / \alpha} \mathrm{L}_{0}<\mathrm{V}_{\mathrm{p}} \tau<\mathrm{m} \mathrm{L}_{0}$ & $\mathrm{~mL} \mathrm{~L}_{0}<\mathrm{V}_{\mathrm{p}} \tau$ \\
\hline
\end{tabular}

Step 1. We have $\omega=\frac{\mathrm{v}_{\mathrm{p}}}{\mathrm{r}}, \sigma=\frac{\mathrm{K}}{\sqrt{\mathrm{r}}}$ and $\varepsilon=\frac{\mathrm{u}}{\mathrm{r}}$ everywhere in the specimen. Thus, for each asymptotic constitutive law, we can compute its spatial domain of existence, as well as the expressions of $\varepsilon, \mathrm{u}$ and $\mathrm{G}_{\text {local }} \equiv \sigma \mathrm{u}$ (the "local energy release rate") in the domain. Proceeding this way, we fill the first six lines of the table 1.

Step 2. Let $L$ be the length of the cohesive zone. It is set by the condition $\sigma_{\mathrm{p}} / \delta=$ $\sigma(\mathrm{r}=\mathrm{L}) / \mathrm{u}(\mathrm{r}=\mathrm{L})$ where $\sigma_{\mathrm{p}}$ and $\delta$ are material constants such that $\Gamma_{\text {intrinsic }}=\sigma_{\mathrm{p}} \delta$. Its detailed expression will therefore depend on the domain (defined as in step 1) surrounding the cohesive zone. Doing so, we obtain the next two lines of the table.

$\underline{\text { Step 3 }}$. The three expressions of L obtained in step 2 are a priori different, implying that $\mathrm{L}$ varies with the load applied to the specimen. One deduces from these expressions the range of crack growth rate for which each domain is immediately surrounding the cohesive zone. This leads to the last line of the table.

Step 4. Let $\mathrm{W}$ be the specimen size, typically a PS specimen height. The $G\left(V_{p}\right)$ relation is found by taking $\Gamma_{\text {intrinsic }}=\mathbf{G}_{\text {local }}(\mathbf{r}=\mathbf{L})$ and $\mathbf{G}=\mathbf{G}_{\text {local }}(\mathbf{r}=\mathbf{W})$. Various situations can be encountered depending on how $\mathrm{W}$ compares with the spatial limits $\mathrm{L}, \mathrm{r}_{\mathrm{h}}$ (hard solid outer radius) and $\mathrm{r}_{\mathrm{s}}$ (soft solid $\underline{\text { inner radius). }}$

For an infinite specimen, $G=\frac{\mathrm{K}^{2}}{\mathrm{E}_{0}}$ and thus $\frac{\mathrm{G}}{\Gamma_{\text {intrinsic }}}=\frac{\mathrm{K}^{2}}{\mathrm{E}_{0} \mathrm{G}_{\text {local }}(\mathrm{r}=\mathrm{L})}$ in any case, 
since the zone near the clamps will always remain in the soft solid domain. One readily finds

$$
\frac{\mathrm{G}}{\Gamma_{\text {intrinsic }}}=\left\{\mathrm{m}\left(\frac{\mathrm{V}_{\mathrm{p}} \tau}{\mathrm{L}_{\infty}}\right)^{\frac{\alpha}{\alpha+1}}=\mathrm{m}\left(\frac{\mathrm{V}_{\mathrm{p}} \tau}{\mathrm{L}_{\infty}}\right)^{\frac{1}{\beta}}\right\} \text { if }\left\{\begin{array}{c}
\mathrm{V}_{\mathrm{p}} \tau<\mathrm{m}^{-1 / \alpha} \mathrm{L}_{0} \\
\mathrm{~m}^{-1 / \alpha} \mathrm{L}_{0}<\mathrm{V}_{\mathrm{p}} \tau<\mathrm{mL}_{0} \\
\mathrm{~mL}_{0}<\mathrm{V}_{\mathrm{p}} \tau
\end{array}\right\}
$$

Remarkably, we end up with the same result as with our former treatment, including the occurrence of a Paris regime characterized by the same exponent $\beta$ and the same expression for $\Gamma_{\mathrm{c}}$.

For a finite specimen however, the preceding results will stop holding once $r_{s}$ reaches $\mathrm{W}$. The exact consequences depend on the $\mathrm{W}$ value.

Assuming first $\mathbf{m}^{\boldsymbol{\beta}} \mathbf{L}_{\mathbf{0}}<\mathbf{W}, \mathrm{r}_{\mathrm{s}}=\mathrm{W}$ happens only after the cohesive zone is surrounded by hard solid, so that the $\mathrm{G}=\Gamma_{\mathrm{c}}$ plateau is still observable experimentally. Once the liquid domain has reached the clamps, $\Gamma_{\text {intrinsic }}=\frac{\mathrm{K}^{2}}{\mathrm{E}_{\infty}}$ and $\frac{\mathrm{G}}{\Gamma_{\text {intrinsic }}}=$ $\frac{\mathrm{E}_{\infty} \mathrm{G}_{\text {local }}(\mathrm{r}=\mathrm{W})}{\mathrm{K}^{2}}$, and (13) must be supplemented by

$$
\frac{G}{\Gamma_{\text {intrinsic }}}=\left\{\left(\frac{\mathrm{W}}{\mathrm{V}_{\mathrm{p}} \tau}\right)^{\alpha}\right\} \text { if }\left\{\begin{array}{c}
\mathrm{m}^{-1 / \alpha} \mathrm{W}<\mathrm{V}_{\mathrm{p}} \tau<\mathrm{W} \\
\mathrm{W}<\mathrm{V}_{\mathrm{p}} \tau
\end{array}\right\}
$$

The corresponding $\mathrm{G}\left(\mathrm{V}_{\mathrm{p}}\right)$ curve therefore exhibits a decreasing portion after having reached the plateau of height $\mathrm{m} \Gamma_{\text {intrinsic. }}$ It is qualitatively consistent with results of peeling tests carried on poorly crosslinked polymers, to which this study aimed at. This was the only situation envisaged in the original papers. Yet, it can be unrealistic in practice, since for $\mathrm{L}_{0}=10 \mathrm{~nm}$ it requires $\mathrm{W}>10 \mathrm{~mm}$ to 10 meters (!) with the above-mentioned $\mathrm{m}$ and $\beta$ values.

Assuming next $\mathbf{L}_{\mathbf{0}}<\mathbf{W}<\mathbf{m}^{\boldsymbol{\beta}} \mathbf{L}_{\mathbf{0}}, \mathrm{r}_{\mathrm{s}}=\mathrm{W}$ now happens before the cohesive zone is surrounded by hard solid, so the previous plateau is not observable anymore, and the material exhibits a different "effective" $\Gamma_{c}$ depending on the specimen dimensions. More precisely, the second line in (13) holds only until $\mathrm{V}_{\mathrm{p}} \tau=\mathrm{m}^{-1 / \alpha} \mathrm{W}$ $(<\mathrm{m} \mathrm{L})$, where the "effective" $\Gamma_{\mathrm{c}}$ is attained :

$$
\frac{\Gamma_{\mathrm{c}}}{\Gamma_{\text {intrinsic }}}=\left(\frac{\mathrm{W}}{\mathrm{L}_{0}}\right)^{\frac{\alpha}{\alpha+1}}=\left(\frac{\mathrm{W}}{\mathrm{L}_{0}}\right)^{\frac{1}{\beta}}
$$

For example, with $\mathrm{L}_{0}=10 \mathrm{~nm}, \mathrm{~W}=10 \mathrm{~mm}$ and $\beta=3$ for instance, $\Gamma_{\mathrm{c}} / \Gamma_{\text {intrinsic }}$ would be limited to 100 . Besides, the third line in (13) must be modified.

If $\mathbf{m} \mathbf{L}_{\mathbf{0}}<\mathbf{W}<\mathbf{m}^{\beta} \mathbf{L}_{\mathbf{0}}$, it is replaced by 


$$
\begin{aligned}
& \frac{G}{\Gamma_{\text {intrinsic }}} \\
& =\left\{\begin{array}{c}
\left(\frac{W}{L}\right)^{\alpha}=\left(\frac{W}{L_{\infty}}\right)^{\alpha}\left(\frac{L_{\infty}}{V_{p} \tau}\right)^{\frac{\alpha^{2}}{\alpha+1}} \\
\left(\frac{W}{V_{p} \tau}\right)^{\alpha} \\
1
\end{array}\right\} \text { if }\left\{\begin{array}{c}
m^{-1 / \alpha} W<V_{p} \tau<m_{0} \\
m L_{0}<V_{p} \tau<W \\
W<V_{p} \tau
\end{array}\right\}
\end{aligned}
$$

Whereas if $\mathbf{L}_{\mathbf{0}}<\mathbf{W}<\mathbf{m} \mathbf{L}_{\mathbf{0}}$, it is replaced by

$$
\begin{aligned}
& \frac{\mathrm{G}}{\Gamma_{\text {intrinsic }}} \\
& =\left\{\left(\frac{\mathrm{W}}{\mathrm{L}}\right)^{\alpha}=\left(\frac{\mathrm{W}}{\mathrm{L}_{\infty}}\right)^{\alpha}\left(\frac{\mathrm{L}_{\infty}}{\mathrm{V}_{\mathrm{p}} \tau}\right)^{\frac{\alpha^{2}}{\alpha+1}}\right\} \text { if }\left\{\begin{array}{c}
\mathrm{m}^{-1 / \alpha} \mathrm{W}<\mathrm{V}_{\mathrm{p}} \tau<\left(\frac{\mathrm{W}}{\mathrm{L}_{\infty}}\right)^{1 / \alpha} \mathrm{W} \\
\left(\frac{\mathrm{W}}{\mathrm{L}_{\infty}}\right)^{1 / \alpha} \mathrm{W}<\mathrm{V}_{\mathrm{p}} \tau
\end{array}\right\}
\end{aligned}
$$

\subsection{Introducing non-linearity in the constitutive equation}

Focusing exclusively on linear viscoelasticity is far too restrictive for filled polymers, which exhibit various nonlinearities at high strains as well as a supplementary source of hysteresis : Mullins effect. In the framework presented here, the better resistance to static crack growth of a filled polymer in comparison to its unfilled homolog is attributed - at least partially - to an increase of $\Gamma_{\text {dissipation }}$ brought by Mullins effect. Interestingly, as previously mentioned, the so-called multi-networks (various standard polymer networks interpenetrated into each other) also enjoy a high toughness and a mechanical behavior reminiscent of Mullins effect [61]. The microscopic origin of Mullins effect may be different in these two classes of materials (cavitation/decohesion in filled polymers vs. localized chains ruptures in multi-networks), but a beneficial impact of Mullins hysteresis onto $\Gamma_{\text {dissipation }}$ is expected in both cases.

Once again, this line of reasoning prompted different works [119, 120, 128]. Zhang [120] starts with the decomposition $\mathrm{G}=\Gamma_{\text {intrinsic }}+\Gamma_{\text {dissipation. }} \Gamma_{\text {dissipation }}$ is assumed proportional to the "ultimate" hysteresis $\mathrm{H}\left(\mathrm{Y}_{\text {rupture }}\right)$, where like in equation (5), $\mathrm{Y}_{\text {rupture }}$ denotes the minimum height at which the material reaches there its stress at break, with a front factor homogeneous to a length. A length scale manifestly relevant to this problem is $\mathrm{G} / \mathrm{W}_{\text {rupture }}$. Therefore the authors were led to guess $\Gamma_{\text {dis- }}$ sipation $=\alpha G h_{\text {rupture }}$ where $h_{\text {rupture }} \equiv \frac{\mathrm{H}\left(\mathrm{Y}_{\text {rupture }}\right)}{\mathrm{W}_{\text {rupture }}}(<1)$. $\alpha$ was found by fitting the results of a campaign of Finite Element Analyses during which the material parameters describing the Mullins effect (modeled with an Ogden-Roxburgh law) and the 
cohesive zone were systematically varied. They obtained eventually

$$
\mathrm{G}=\frac{\Gamma_{\text {intrinsic }}}{1-\alpha \mathrm{h}_{\text {rupture }}} \text { with } \alpha \approx 0.33+\frac{0.034}{\mathrm{~m} / \mathrm{W}_{\text {rupture }}+0.045} \text { (18). }
$$

$\mathrm{r}, \mathrm{m}$ and $\beta$ (set to 0.1 in the article) are material parameters quantifying the Mullins hysteresis : if the energy density provided during the first loading equals $\mathrm{W}$, the Mullins hysteresis reads " $\mathrm{h}(\mathrm{W}) \mathrm{W}$ " where

$$
h(W)=\frac{1}{r} f\left[\left(\beta+\frac{m}{W}\right)^{-1}\right] \text { with } f(x) \equiv \frac{1}{x} \int_{0}^{x} \operatorname{erf}(y) d y \quad(19) \text {. }
$$

Especially, the smaller m, the greater the hysteresis of small amplitude cycles, and thus the greater the hysteresis far from the crack tip. This remark will soon be useful. Qi [119] gave an analytic derivation of this result based on equation (2). The maximum energy density along a line parallel to a mode I crack in a Neo-Hookean material reads $\mathrm{W}(\mathrm{Y})=\frac{\mathrm{G}}{2 \pi \mathrm{Y}}$ according to asymptotic developments. Using a slightly modified version of this expression to take far fields and Mullins softening into account, the authors reported it into (19), and (19) into (2). Proceeding this way, they obtained an $\alpha$ expression comparing well with (18).

Besides, if $\mathbf{m} \rightarrow \mathbf{0}$, we noted above that the dissipation zone can extend to the clamps, so the measured $\mathbf{G}$ can depend on the specimen geometry, ceasing to be an intrinsic material property. Some FEA confirmed this intuition, FEA that were themselves well reproduced by the analytic theory. $\frac{G}{\Gamma_{\text {intrinsic }}}$ appears to depend on a dimensionless parameter $\chi=\frac{2 \mathrm{H}_{0}}{\Gamma_{\text {intrinsic }} / \mathrm{W}_{\text {rupture }}}$ which is the ratio of the PS specimen height to the cohesive zone length.

\subsection{Experimental tests of the preceding theories}

Viscoelastic behavior: Knauss and his co-workers applied successfully various theories to a polyurethane. The model developed in Mueller and Knauss [38] matched well the experimental points. It relied on an analysis of the viscoelastic relaxation in the cohesive zone and its prediction read ( $\Delta$ a being a material constant, set to $13.4 \mathrm{~nm}$ by the fitting procedure):

$$
\mathrm{G}\left(\mathrm{V}_{\mathrm{p}}\right)=\frac{\Gamma_{\text {intrinsic }}}{2 \mathrm{E}_{0} \mathrm{D}\left(\Delta \mathrm{a} / \mathrm{V}_{\mathrm{p}}\right)} \text { where } \mathrm{D}(\mathrm{t}) \equiv \frac{1}{\mathrm{t}} \int_{0}^{\mathrm{t}}\left(1-\frac{\mathrm{u}}{\mathrm{t}}\right) \mathrm{J}(\mathrm{u}) \mathrm{du} \text { (20). }
$$

Contrary to the appearances, this result is actually quite similar to (9). Indeed, using a Kramers-Kronig relation, one can recast the denominator of (20) :

$$
J(t)=\frac{1}{E_{0}}+\frac{2}{\pi} \int_{0}^{+\infty} J^{\prime \prime}(\omega) \cos (\omega t) \frac{d \omega}{\omega} \Rightarrow D(t) \approx \frac{1}{2 E_{0}}-\frac{1}{\pi} \int_{0}^{1 / t}\left|J^{\prime \prime}(\omega)\right| \frac{d \omega}{\omega}(21) .
$$

(We used the approximation $(1-\cos (\mathrm{x})) / \mathrm{x}^{2} \approx 1 / 2 \mathcal{H}(1-\mathrm{x})$.) The only distinct feature is the constancy of $\Delta \mathrm{a}$. So this success suggests also a success of (9).

Later[109, 110], they developed a refined version of this early model, which proved to be equally successful. In both cases, the model predicts a correct Paris exponent 
$\beta$. In fact, these data are consistent with the rule $\beta=1+1 / \alpha$ : experiments suggest $\alpha \approx 0.8$ (read on master curves of dynamic moduli) and $\beta \approx 2.4$ (read on curves of $\mathrm{V}_{\mathrm{p}}$ vs. $\varepsilon_{\infty}, \varepsilon_{\infty}$ being the macroscopic strain applied to the PS specimen, so that $\mathrm{G} \propto$ $\varepsilon_{\infty}{ }^{2}$ ), in reasonable agreement with the theoretical prediction $\beta \approx 2.25$. With this material, $\mathrm{m} \approx 1725 \mathrm{MPa} / 2.75 \mathrm{MPa} \approx 627$, and the predicted $\Gamma_{\mathrm{c}}\left(=\mathrm{m} \Gamma_{0}\right)$ seems in agreement with experiment, though the final plateau is not sufficiently well observed to be categorical. Assuming $\mathrm{L}_{0}=10 \mathrm{~nm}$ for the cohesive length at low $\mathrm{V}_{\mathrm{p}}$, the De Gennes criterion to avoid finite size effects reads $W>627^{2.25} \times 10 \mathrm{~nm}=2 \mathrm{~cm}$ : it was indeed satisfied in Knauss experiments, where $\mathrm{W}=3.5 \mathrm{~cm}$. Incidentally, Christensen [112] also managed to fit this set of experimental results using a theory of his own, explicitly relying on an energy budget.

Saulnier [129] carried adhesion experiments on an un-crosslinked polydimethylsiloxane (PDMS) of large molecular weight. They confirmed De Gennes predictions (with $\alpha=1$ ) regarding the decrease of fracture energy at high crack growth rates - equation (14) - as well as the opening displacement of the crack lips : $\mathrm{u} \propto$ $\mathrm{x}^{1 / 2}$ near the crack tip where the material behaves as a hard solid, $\mathrm{u} \propto \mathrm{x}^{3 / 2}$ farther from the crack tip where the material becomes liquid-like.

Gent $[124,125]$ carried peeling tests on various crosslinked polymers of variable $T_{\mathrm{g}}$. He found that the $\mathrm{G} / \Gamma_{\text {intrinsic }}$ vs. $V_{\mathrm{p}}$ master-curves were relatively independent of the polymer, like the $E^{\prime}(\omega) / E_{0}$ vs. $\omega$ master-curves (though to a smaller extent), and speculated, from the resemblance between these, that $\frac{G}{\Gamma_{\text {intrinsic }}}=\frac{E^{\prime}\left(V_{p} / d\right)}{E_{0}}$ with $\mathrm{d}$ some material constant. Unfortunately the exponents of the power laws fitting the glass transition regime did not match : $\beta^{-1}=0.3$ for the peeling energy, $\alpha=0.6$ for the storage modulus. Trying anyway to fit the model onto experiment, he found $\mathrm{d} \approx$ $0.1 \mathrm{~nm}$, or more largely $0.01 \mathrm{~nm}<\mathrm{d}<1 \mathrm{~nm}$, some unrealistically low values. Besides, $\Gamma_{\mathrm{c}} / \Gamma_{\text {intrinsic }}$ appears slightly greater than $\mathrm{E}_{\infty} / \mathrm{E}_{0}$. But the theories explored in the preceding paragraphs point rather to $d \propto \mathrm{G}$, implying $\frac{1}{\beta}=\frac{\alpha}{\alpha+1}$, i.e. $\beta^{-1}=0.375$ in the present case, which is closer to experiment. One can hope that this improvement will also bring the $\mathrm{d}$ range towards more sensible values. In fact, this improvement could be combined with other features not addressed by the models we reviewed but envisaged by Gent : nonlinear effects near the crack tip, intermittent propagation "in a stick-slip fashion". This last feature implies that the instantaneous $\mathrm{V}_{\mathrm{p}}$ can be much higher than the average $\mathrm{V}_{\mathrm{p}}$, which is the one measured : one should keep this idea in mind when considering cyclic crack growth.

Extension to cyclic crack growth and to Mullins effect dissipation: Klüppel surveyed the ability of the models we reviewed to reproduce the cyclic crack growth curves measured on filled and unfilled polymer[130]. The author used crosslinked S-SBR and Ethylene Propylene Diene Monomer (1.7 phr S + $2.5 \mathrm{phr}$ CBS) filled or not with $60 \mathrm{phr}$ of N550 carbon black. He focused his attention on Paris law slopes, and found that the theory matched reasonably with experiment. This is particularly striking because the theory in question has been devised exclusively for static crack 
growth, and besides it ignores the nonlinearities and the Mullins effect typical of filled polymers. This remark suggests to check if the Paris law intercepts with the $\mathrm{Y}$-axis are equally well reproduced by the theory, namely equation (11) with $\mathrm{B}=1$. It is an uncertain task since some key quantities $\left(\Gamma_{\text {intrinsic }}\right.$ and $\left.\mathrm{W}_{\text {rupture }}\right)$ are missing in the article : we must guess them and see what we get. Using notably $\Gamma_{\text {intrinsic }} \approx 50$ (resp. 100) J.m $\mathrm{m}^{-2}$ in the unfilled (resp. filled) case, we find at $\mathrm{G} \approx 3 \mathrm{~kJ} . \mathrm{m}^{-2}, 4 \mathrm{~Hz}$ and ambient temperature : in unfilled S-SBR, $\mathrm{V}_{\mathrm{p}} \approx 40 \mathrm{~m} . \mathrm{s}^{-1}$ theoretically vs. $\mathrm{V}_{\mathrm{p}} \approx 10$ $\mathrm{nm}$. cycle $^{-1}=40 \mathrm{~nm} \cdot \mathrm{s}^{-1}$ experimentally ; in filled S-SBR, $\mathrm{V}_{\mathrm{p}} \approx 4 \mathrm{~m} \cdot \mathrm{s}^{-1}$ theoretically vs. $\mathrm{V}_{\mathrm{p}} \approx 4 \mathrm{~nm}$.cycle $\mathrm{e}^{-1}=40 \mathrm{~nm} \cdot \mathrm{s}^{-1}$ experimentally. These estimates must be taken with caution owing to the mentioned uncertainties. Nevertheless, the discrepancy between our estimates and the measurements is such that we can consider that the theory fails to reproduce the intercept with the Y-axis of the Paris law.

Zhang [120] checked that it could reproduce by FEA the onset of crack propagation in a multi-network hydrogel considered to exhibit Mullins effect only. Constitutive law parameters were identified on cycles of increasing maximum strain applied in pure shear. The propagation threshold $\mathrm{G}$ was measured after various prestrains - applied to the uncracked specimen - between 0 and the strain at break (as high as 8 here). It appears to decrease with pre-strain, reaching a plateau (400 J.m${ }^{2}$ ) for the highest pre-strains, to be identified with the virgin $\Gamma_{\text {intrinsic }}$ (though one could argue that high pre-strains could damage enough the material to diminish its

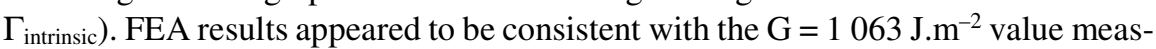
ured with the virgin material. Incidentally, this experiment proves that the intrinsic resistance to crack growth represents here only $38 \%$ of $\mathrm{G}$ in the virgin state, the remaining $62 \%$ being brought by macroscopic dissipation.

Qi [119] put the pre-strain effect in equations. The line of reasoning is as follows: the horizontal strips whose strain remains below the pre-strain cannot dissipate by Mullins effect (strips close to the clamps), the dissipation being thus confined to a central strip, where it is moreover smaller than in the virgin state. These statements explain qualitatively why $\Gamma_{\text {dissipation }}$ must decrease with pre-strain : the pre-strain diminishes the capacity of the material to dissipate when a crack propagates. The agreement with experiment is even quantitative, as shown in the article.

Wunde et al. [131, 132] carried experiments on cured CB-filled NR-based polymer blends allowing an estimation of $\Gamma_{\text {dissipation }} / \mathrm{G}$. For the 4 mixes of the study and various macroscopic strain, they measured by Digital Image Correlation the displacement and strain fields in notched and loaded PS specimens, that they combined with the constitutive laws - modelling Mullins effect and viscoelasticity - identified independently to compute the Rice- or $\mathcal{J}$-integral on various circles $\mathrm{C}$ centered on the crack tip. (They considered both components of $\int_{C} \Sigma_{\mathrm{ij}} \mathrm{ds}$, but we focus here on the sole forward component). $\mathcal{J}$ appears to increase with the circle radius $\mathrm{R}$, consistently with $\mathcal{J}(\mathrm{R}=0)=\Gamma_{\text {intrinsic }}$ and $\mathrm{G}=\mathcal{J}(\mathrm{R}=+\infty)$ by construction of $\mathcal{J}$ and with the inequality $\Gamma_{\text {intrinsic }}<\mathrm{G}$ for a dissipative material. Actually, the difference between these limits is $\Gamma_{\text {dissipation. The analysis is complicated by a lack of resolution for } \mathrm{R}<}$ $0.5 \mathrm{~mm}$ and by the fact that $\mathcal{J}(\mathrm{R}=+\infty)$ becomes greater than $\mathrm{G}$ (computed by the 
Rivlin-Thomas formula) above $40 \%$ macroscopic strain. Despites these difficulties, the authors estimate that all in all, $\Gamma_{\text {dissipation }}$ represents $90 \%$ of $\mathrm{G}$. These experiments also demonstrate that $\mathcal{J}$ reaches $\mathrm{G}$ for $\mathrm{R}>1$ to $5 \mathrm{~mm}$ (for macroscopic strains between 10 and $60 \%$ ) : these are macroscopic dimensions, which legitimate the qualification of $\Gamma_{\text {dissipation as a macroscopic dissipation. Especially, these dimensions }}$ demonstrate clearly that crack growth can be accompanied by energy dissipation quite far from the crack tip, where no macroscopic breakage occurs.

Slootman [44] introduced in mono- and multi-networks of polymers a known amount of a mechanophore having the property of becoming fluorescent upon breakage. The materials being transparent, they could be measured by optical confocal microscopy the spatial distribution of this fluorescence, and therefore (via an appropriate calibration) the spatial distribution of the number of broken mechanophores, and finally of overall broken bonds. These distributions were measured along the lips of a crack propagated for various loadings and temperatures. $\Gamma_{\text {intrinsic }}$ is deduced by integrating the distribution (for a unit propagated surface) and multiplying the integral by $64 \mathrm{~kJ}^{\mathrm{mol}}{ }^{-1}$, the energetic cost of a single breakage according to Wang ${ }^{137}$. Most remarkably, the author demonstrated that $: \Gamma_{\text {intrinsic }}$ increases with the loading, that is with $G$ or $V_{p}$, going from the Lake and Thomas estimate for $V_{p}$ $\rightarrow 0$ up to 100 times this value at high $\mathrm{V}_{\mathrm{p}}$; and that the number of covalent bond scissions varies in the same proportion, with rupture occurring up to a few $100 \mu \mathrm{m}$ far from the crack plane for the highest $V_{p}$. Especially, $\Gamma_{\text {intrinsic }}$ cannot be treated as a material constant, as was done in the works reviewed so far, but as a function of $\mathbf{V}_{\mathbf{p}}$. Notice however that equation (2) and the ones stemming from it can

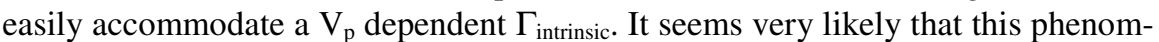
enology also applies to filled polymers, whose filler network is analogous to the first network here and whose polymer matrix is analogous to the second and third networks here. Depending on the tested Single-, Double- or Triple- Network, she found that $\Gamma_{\text {intrinsic }} / \mathrm{G}$ varies between a few $\%$ and a few $10 \%$, and therefore $\Gamma$ dissipation / $\mathrm{G}$ varies between 50 and more than $90 \%$.

\section{Conclusion}

A synthesis of the phenomenology of ultimate and crack growth properties of elastomers is not straightforward given the diversity of elastomers and used protocols. Nevertheless, despite this difficulty, the huge literature on the topic, completed by some our own experimental works, allows to well identify the different interrelated and complex mechanisms involved in crack growth. In connection with these observations, the theories reviewed in the last part link quantitatively the resistance to crack growth to:

- the ability of the material to dissipate energy, either by viscoelasticity or by Mullins effect ; 
- the distribution of strain and stress around the crack tip (dictated by the constitutive law), which weights the contribution of each horizontal line to the total dissipation accompanying the crack growth ;

- the break properties (limit strain / stress / energy), which define an upper bound for the dissipation integrals.

These theories have been validated experimentally in various situations. They can be useful to material designers because they allow the replacement of lengthy or sophisticated crack growth experiments by faster and simpler mechanical characterization of unnotched specimen until break, and because they offer a mean to infer what "customary" material property (moduli, break properties) to tune and in which direction to achieve an enhanced resistance to crack growth. Especially, the theories involving dynamic moduli can suggest compromises between Rolling Resistance (RR) and endurance in tires via the difference of frequency ranges relevant to each performance. This situation is reminiscent of the known compromise between RR and grip. And in fact, the analogy goes deeper : the well-known viscoelastic contribution to the friction coefficient $\mu$ is equivalent to the viscoelastic contribution in $\Gamma_{\text {dissipation }}$ (see e.g. our equation (9)), the role of crack tip singularity in endurance is played by road asperities in grip, and the integral over all distances $Y$ from the crack plan is replaced in the grip case by the integral over asperity sizes and tread band depth.

Though these theories are encouraging, they still suffer of various shortcomings. The most obvious from a practical standpoint is their inability so far to handle cyclic crack growth : they have been thought for static crack growth, and their generalizations to the cyclic case is not straightforward. They also often treat $\Gamma_{\text {intrinsic }}$ and $\mathrm{W}_{\text {rup- }}$ ture as material constants, although they are susceptible to vary with strain rate and thus $\mathrm{V}_{\mathrm{p}}$. Finally, it is highly desirable to now quantitatively relate them to the differents fields measurable at the crack tip and reviewed in chapters 2 and 3 (including cavitation and degree of Strain Induced Crystallization). These missing features are as many subjects for future researches.

\section{Reference}

1. Creton C, Ciccotti M (2016) Fracture and adhesion of soft materials: a review. Rep Prog Phys 79:046601

2. Gent AN, Mars WV (2013) Strength of Elastomers. In: The Science and Technology of Rubber. Elsevier, pp 473-516

3. Mars WV, Fatemi A (2004) Factors that Affect the Fatigue Life of Rubber: A Literature Survey. Rubber Chem Technol 77:391-412

4. Tee YL, Loo MS, Andriyana A (2018) Recent advances on fatigue of rubber after the literature survey by Mars and Fatemi in 2002 and 2004. Int J Fatigue 110:115-129

5. Grellmann W, Heinrich G, Kaliske M, Klüppel M, Schneider K, Vilgis ThA (2013) Fracture Mechanics and Statistical Mechanics of Reinforced Elastomeric Blends. Springer-Verlag Berlin Heidelberg, Berlin; Heidelberg

6. Lake GJ (1995) Fatigue and Fracture of Elastomers. Rubber Chem Technol 68:435-460 
7. Nonoyama T, Wada S, Kiyama R, Kitamura N, Mredha MdTI, Zhang X, Kurokawa T, Nakajima T, Takagi Y, Yasuda K, Gong JP (2016) Double-Network Hydrogels Strongly Bondable to Bones by Spontaneous Osteogenesis Penetration. Adv Mater 28:6740-6745

8. Kamat S, Su X, Ballarini R, Heuer AH (2000) Structural basis for the fracture toughness of the shell of the conch Strombus gigas. Nature 405:1036-1040

9. Sen D, Buehler MJ (2011) Structural hierarchies define toughness and defect-tolerance despite simple and mechanically inferior brittle building blocks. Sci Rep 1:35

10. Gong JP, Katsuyama Y, Kurokawa T, Osada Y (2003) Double-Network Hydrogels with Extremely High Mechanical Strength. Adv Mater 15:1155-1158

11. Higuchi Y, Saito K, Sakai T, Gong JP, Kubo M (2018) Fracture Process of Double-Network Gels by Coarse-Grained Molecular Dynamics Simulation. Macromolecules 51:3075-3087

12. Lavoie SR, Millereau P, Creton C, Long R, Tang T (2019) A continuum model for progressive damage in tough multinetwork elastomers. J Mech Phys Solids 125:523-549

13. Laiarinandrasana L, Morgeneyer TF, Proudhon H, N'guyen F, Maire E (2012) Effect of Multiaxial Stress State on Morphology and Spatial Distribution of Voids in Deformed Semicrystalline Polymer Assessed by X-ray Tomography. Macromolecules 45:4658-4668

14. Rublon P, Huneau B, Verron E, Saintier N, Beurrot S, Leygue A, Mocuta C, Thiaudière D, Berghezan D (2014) Multiaxial deformation and strain-induced crystallization around a fatigue crack in natural rubber. Eng Fract Mech 123:59-69

15. Kallungal J, Chazeau L, Chenal J-M, Adrien J, Maire E, Barres C, Cantaloube B, Heuillet P (2019) Methodology for 3D characterization of microstructural defects in filled polymer using Xray Tomography. In: Huneau B, Le Cam J-B, Marco Y, Verron E (eds) Constitutive Models for Rubber XI, 1st ed. CRC Press, pp 77-81

16. Saintier N (2001) Fatigue multiaxiale dans un élastomère de type NR chargé : mécanismes d'endommagment et critère local d'amorçage de fissure. 225

17. Saintier N, Cailletaud G, Piques R (2006) Crack initiation and propagation under multiaxial fatigue in a natural rubber. Int $J$ Fatigue 28:61-72

18. Lake GJ, Lindley PB (1964) Cut growth and fatigue of rubbers. II. Experiments on a noncrystallizing rubber. J Appl Polym Sci 8:707-721

19. Lindley PB (1974) Non-Relaxing Crack Growth and Fatigue in a Non-Crystallizing Rubber. Rubber Chem Technol 47:1253-1264

20. Rivlin RS, Thomas AG (1953) Rupture of rubber. I. Characteristic energy for tearing. J Polym Sci 10:291-318

21. Roucou D, Diani J, Brieu M, Witz J-F, Mbiakop-Ngassa A (2018) Experimental investigation of elastomer mode I fracture: an attempt to estimate the critical strain energy release rate using SENT tests. Int J Fract 209:163-170

22. Thomas AG (1994) The Development of Fracture Mechanics for Elastomers. Rubber Chem Technol 67:50-67

23. Yeoh OH (2003) Fracture Mechanics of Bond Failure in the "Pure Shear" Test Piece. Rubber Chem Technol 76:483-494

24. Greensmith HW (1963) Rupture of rubber. X. The change in stored energy on making a small cut in a test piece held in simple extension. J Appl Polym Sci 7:993-1002

25. Lindley PB (1972) Energy for crack growth in model rubber components. J Strain Anal 7:132140

26. Carbone G, Persson BNJ (2005) Crack motion in viscoelastic solids: The role of the flash temperature. Eur Phys J E 17:261-281

27. Smith TL (1958) Dependence of the ultimate properties of a GR-S rubber on strain rate and temperature. J Polym Sci 32:99-113

28. Bueche F, Halpin JC (1964) Molecular Theory for the Tensile Strength of Gum Elastomers. J Appl Phys 35:36-41

29. Kok CM, Yee VH (1986) The effects of crosslink density and crosslink type on the tensile and tear strengths of NR, SBR and EPDM gum vulcanizates. Eur Polym J 22:341-345

30. Lake GJ, Lawrence CC, Thomas AG (2000) High-Speed Fracture of Elastomers: Part I. Rubber Chem Technol 73:801-817 
31. Tsunoda K, Busfield JJC, Davies CKL, Thomas AG (2000) Effect of materials variables on the tear behaviour of a non-crystallising elastomer. J Mater Sci 35:5187-5198

32. Papadopoulos IC, Thomas AG, Busfield JJC (2008) Rate transitions in the fatigue crack growth of elastomers. J Appl Polym Sci 109:1900-1910

33. Fukahori Y, Sakulkaew K, Busfield JJC (2013) Elastic-viscous transition in tear fracture of rubbers. Polymer 54:1905-1915

34. Horst T, Heinrich G (2008) Crack propagation behavior in rubber materials. Polym Sci Ser A 50:583-590

35. Mullins L (1959) Rupture of rubber - Part IX : role of hysteresis in the tearing of rubber. Trans Proc Inst Rubber Ind 35:213-222

36. Lake GJ, Yeoh OH (1978) Measurement of rubber cutting resistance in the absence of friction. Int J Fract 14:509-526

37. Robertson CG, Stoček R, Kipscholl C, Mars WV (2019) Characterizing the Intrinsic Strength (Fatigue Threshold) of Natural Rubber/Butadiene Rubber Blends. Tire Sci Technol 47:292-307

38. Mueller HK, Knauss WG (1971) The Fracture Energy and Some Mechanical Properties of a Polyurethane Elastomer. Trans Soc Rheol 15:217-233

39. Ahagon A, Gent AN (1975) Threshold fracture energies for elastomers. J Polym Sci Polym Phys Ed 13:1903-1911

40. Bhowmick AK, Gent AN, Pulford CTR (1983) Tear Strength of Elastomers under Threshold Conditions. Rubber Chem Technol 56:226-232

41. Gent AN, Tobias RH (1982) Threshold Tear Strength of Some Molecular Networks. In: Mark JE, Lal J (eds) Elastomers and Rubber Elasticity. American Chemical Society, Washington, D. C., pp 367-376

42. Stoček R, Stěnička M, Zádrapa P (2020) Future trends in predicting the complex fracture behaviour of rubber materials. Contin Mech Thermodyn

43. Lake GJ, Thomas AG (1967) The strength of highly elastic materials. Proc R Soc Lond Ser Math Phys Sci 300:108-119

44. Slootman J (2019) Quantitative detection of damage in soft materials using mechano-fluorescence. l'Ecole Supérieure de Physique et de Chimie Industrielles de la ville de Paris (ESPCI Paris) 45. De Almeida A, Chazeau L, Vigier G, Marque G, Goutille Y (2017) Ultimate and toughness properties of $\gamma$-irradiated EPDM. Eur Polym J 97:178-187

46. Kadir A, Thomas AG (1981) Tear Behavior of Rubbers Over a Wide Range of Rates. Rubber Chem Technol 54:15-23

47. Lake GJ, Lindley PB (1965) The mechanical fatigue limit for rubber. J Appl Polym Sci 9:1233-1251

48. Paris P, Erdogan F (1963) A Critical Analysis of Crack Propagation Laws. J Basic Eng 85:528-533

49. Lake GJ, Lindley PB (1964) Cut growth and fatigue of rubbers. II. Experiments on a noncrystallizing rubber. J Appl Polym Sci 8:707-721

50. Long R, Hui C-Y (2015) Crack tip fields in soft elastic solids subjected to large quasi-static deformation - A review. Extreme Mech Lett 4:131-155

51. Horiuchi S, Dohi H (2006) Nanoimaging and Spectroscopic Analysis of Rubber/ZnO Interfaces by Energy-Filtering Transmission Electron Microscopy. Langmuir 22:4607-4613

52. Tobolsky AV, Lyons PF (1968) Tensile strength of rubbers. J Polym Sci Part -2 Polym Phys 6:1561-1566

53. Colin X, Audouin L, Verdu J (2007) Kinetic modelling of the thermal oxidation of polyisoprene elastomers. Part 3: Oxidation induced changes of elastic properties. Polym Degrad Stab 92:906-914

54. Howse S, Porter C, Mengistu T, Pazur RJ (2018) Experimental determination of the quantity and distribution of chemical crosslinks in unaged and aged natural rubber, part 1: Peroxide vulcanization. Polym Test 70:263-274

55. Kaidou H, Ahagon A (1990) Aging of Tire Parts during Service. II. Aging of Belt-Skim Rubbers in Passenger Tires. Rubber Chem Technol 63:698-712 
56. Langley NR, Polmanteer KE (1974) Relation of elastic modulus to crosslink and entanglement concentrations in rubber networks. J Polym Sci Polym Phys Ed 12:1023-1034

57. Saalwächter K (2012) Microstructure And Molecular Dynamics Of Elastomers As Studied By Advanced Low-Resolution Nuclear Magnetic Resonance Methods. Rubber Chem Technol 85:350-386

58. Legorjujago K (2002) Fatigue initiation and propagation in natural and synthetic rubbers. Int J Fatigue 24:85-92

59. Mark JE, Tang M-Y (1984) Dependence of the elastomeric properties of bimodal networks on the lengths and amounts of the short chains. J Polym Sci Polym Phys Ed 22:1849-1855

60. Buckley GS, Fragiadakis D, Roland CM (2011) Strength enhancement from heterogeneous networks of ethylene-propylene/ethylene-propylene-diene. Rubber Chem Technol 84:520-526

61. Ducrot E, Chen Y, Bulters M, Sijbesma RP, Creton C (2014) Toughening Elastomers with Sacrificial Bonds and Watching Them Break. Science 344:186-189

62. Le Gac P-Y, Albouy P-A, Petermann D (2018) Strain-induced crystallization in an unfilled polychloroprene rubber: Kinetics and mechanical cycling. Polymer 142:209-217

63. Candau N, Chazeau L, Chenal J-M, Gauthier C, Munch E (2016) A comparison of the abilities of natural rubber (NR) and synthetic polyisoprene cis-1,4 rubber (IR) to crystallize under strain at high strain rates. Phys Chem Chem Phys 18:3472-3481

64. Behnke R, Berger T, Kaliske M (2018) Numerical modeling of time- and temperature-dependent strain-induced crystallization in rubber. Int J Solids Struct 141-142:15-34

65. Brüning K, Schneider K, Roth SV, Heinrich G (2012) Kinetics of Strain-Induced Crystallization in Natural Rubber Studied by WAXD: Dynamic and Impact Tensile Experiments. Macromolecules 45:7914-7919

66. Candau N, Laghmach R, Chazeau L, Chenal J-M, Gauthier C, Biben T, Munch E (2015) Temperature dependence of strain-induced crystallization in natural rubber: On the presence of different crystallite populations. Polymer 60:115-124

67. Candau N, Chazeau L, Chenal J-M, Gauthier C, Munch E (2016) Complex dependence on the elastically active chains density of the strain induced crystallization of vulcanized natural rubbers, from low to high strain rate. Polymer 97:158-166

68. Das A, Le HH, Vuorinen J, Heinrich G (2017) Comment on "Monitoring Network and Interfacial Healing Processes by Broadband Dielectric Spectroscopy: A Case Study on Natural Rubber.” ACS Appl Mater Interfaces 9:14547-14551

69. Huneau B (2011) Strain-Induced Crystallization Of Natural Rubber: A Review Of X-Ray Diffraction Investigations. Rubber Chem Technol 84:425-452

70. Khiêm VN, Itskov M (2018) Analytical network-averaging of the tube model: Strain-induced crystallization in natural rubber. J Mech Phys Solids 116:350-369

71. Laghmach R, Candau N, Chazeau L, Munch E, Biben T (2015) Phase field modelling of strain induced crystal growth in an elastic matrix. J Chem Phys 142:244905

72. Li X, Schneider K, Kretzschmar B, Stamm M (2008) Deformation Behavior of PP and PP/ZnO Nanocomposites As Studied by SAXS and WAXS. Macromolecules 41:4371-4379

73. Roth SV, Rothkirch A, Autenrieth T, Gehrke R, Wroblewski T, Burghammer MC, Riekel C, Schulz L, Hengstler R, Müller-Buschbaum P (2010) Spatially Resolved Investigation of Solution Cast Nanoparticle Films by X-ray Scattering and Multidimensional Data Set Classification. Langmuir 26:1496-1500

74. Sotta P, Albouy P-A (2020) Strain-Induced Crystallization in Natural Rubber: Flory's Theory Revisited. Macromolecules 53:3097-3109

75. Flory PJ (1947) Thermodynamics of Crystallization in High Polymers. I. Crystallization Induced by Stretching. J Chem Phys 15:397-408

76. Gent AN, Hindi M (1990) Effect of Oxygen on the Tear Strength of Elastomers. Rubber Chem Technol 63:123-134

77. Kim SG, Lee S-H (1994) Effect of Crosslink Structures on the Fatigue Crack Growth Behavior of NR Vulcanizates with Various Aging Conditions. Rubber Chem Technol 67:649-661 
78. Rublon P, Huneau B, Saintier N, Beurrot S, Leygue A, Verron E, Mocuta C, Thiaudière D, Berghezan D (2013) In situ synchrotron wide-angle X-ray diffraction investigation of fatigue cracks in natural rubber. J Synchrotron Radiat 20:105-109

79. Hamed GR, Park BH (1999) The mechanism of carbon black reinforcement of SBR and NR vulcanizates. Rubber Chem Technol 72:946-959

80. Xiang F, Schneider K, Heinrich G (2020) New observations regarding fatigue crack paths and their fracture surfaces in natural rubber: Influences of R-ratio and pre-load. Int $\mathbf{J}$ Fatigue 135:105508

81. Lee DJ, Donovan JA (1987) Microstructural Changes in the Crack Tip Region of CarbonBlack-Filled Natural Rubber. Rubber Chem Technol 60:910-923

82. Trabelsi S, Albouy P-A, Rault J (2002) Stress-Induced Crystallization around a Crack Tip in Natural Rubber. Macromolecules 35:10054-10061

83. Grasland F, Chenal J-M, Chazeau L, Caillard J, Schach R (2017) Role of SIC on the fatigue properties of NR after realistic aerobic ageing. In: Lion A, Johlitz M (eds) European Conference on Constitutive Models for Rubbers X. CRC Press, Munich, Germany

84. Le Cam J-B, Toussaint E (2010) The Mechanism of Fatigue Crack Growth in Rubbers under Severe Loading: the Effect of Stress-Induced Crystallization. Macromolecules 43:4708-4714

85. Grasland F (2018) Vieillissement du caoutchouc naturel parthermo-oxydation: Etudes de ses conséquences sur lacristallisation sous déformation, la fissuration et larupture. PhD Thesis, Université de Lyon

86. Beurrot S, Huneau B, Verron E (2010) In situ SEM study of fatigue crack growth mechanism in carbon black-filled natural rubber. J Appl Polym Sci NA-NA

87. Zhou W, Li X, Lu J, Huang N, Chen L, Qi Z, Li L, Liang H (2015) Toughening mystery of natural rubber deciphered by double network incorporating hierarchical structures. Sci Rep 4:7502 88. Grasland F, Chazeau L, Chenal J-M, schach R (2019) About thermo-oxidative ageing at moderate temperature of conventionally vulcanized natural rubber. Polym Degrad Stab 161:74-84

89. Grasland F, Chazeau L, Chenal J-M, Caillard J, Schach R (2019) About the elongation at break of unfilled natural rubber elastomers. Polymer 169:195-206

90. Candau N, Laghmach R, Chazeau L, Chenal J-M, Gauthier C, Biben T, Munch E (2015) Influence of strain rate and temperature on the onset of strain induced crystallization in natural rubber. Eur Polym J 64:244-252

91. Chazeau L, Gauthier C, Chenal J-M (2010) Mechanical Properties of Rubber Nanocomposites: How, Why $\ldots$ and Then?

92. Stöckelhuber KW, Das A, Klüppel M, Basu D (2017) Designing of elastomer nanocomposites: from theory to applications. In: Designing of elastomer nanocomposites: from theory to applications, 1st ed. 2017. Springer, Cham

93. Chazeau L, Brown JD, Yanyo LC, Sternstein SS (2000) Modulus recovery kinetics and other insights into the payne effect for filled elastomers. Polym Compos 21:202-222

94. Diani J, Fayolle B, Gilormini P (2009) A review on the Mullins effect. Eur Polym J 45:601612

95. Chenal J-M, Gauthier C, Chazeau L, Guy L, Bomal Y (2007) Parameters governing strain induced crystallization in filled natural rubber. Polymer 48:6893-6901

96. Gabrielle B, Guy L, Albouy P-A, Vanel L, Long DR, Sotta P (2011) Effect of Tear Rotation on Ultimate Strength in Reinforced Natural Rubber. Macromolecules 44:7006-7015

97. Medalia AI (1986) Effect of Carbon Black on Ultimate Proper.Pdf. Rubber Div Am Chem Soc 60:45-60

98. Ramier J, Chazeau L, Gauthier C, Stelandre L, Guy L, Peuvrel-Disdier E (2007) In situ SALS and volume variation measurements during deformation of treated silica filled SBR. J Mater Sci 42:8130-8138

99. Zhang H, Scholz AK, de Crevoisier J, Vion-Loisel F, Besnard G, Hexemer A, Brown HR, Kramer EJ, Creton C (2012) Nanocavitation in Carbon Black Filled Styrene-Butadiene Rubber under Tension Detected by Real Time Small Angle X-ray Scattering. Macromolecules 45:15291543 
100. Le Cam J-B, Huneau B, Verron E, Gornet L (2004) Mechanism of Fatigue Crack Growth in Carbon Black Filled Natural Rubber. Macromolecules 37:5011-5017

101. Millereau P, Ducrot E, Clough JM, Wiseman ME, Brown HR, Sijbesma RP, Creton C (2018) Mechanics of elastomeric molecular composites. Proc Natl Acad Sci 115:9110-9115

102. Xu Z, Jerrams S, Guo H, Zhou Y, Jiang L, Gao Y, Zhang L, Liu L, Wen S (2020) Influence of graphene oxide and carbon nanotubes on the fatigue properties of silica/styrene-butadiene rubber composites under uniaxial and multiaxial cyclic loading. Int J Fatigue 131:105388

103. Dizon ES, Hicks AE, Chirico VE (1974) The Effect of Carbon Black Parameters on the Fatigue Life of Filled Rubber Compounds. Rubber Chem Technol 47:231-249

104. Nie Y, Wang B, Huang G, Qu L, Zhang P, Weng G, Wu J (2010) Relationship between the material properties and fatigue crack-growth characteristics of natural rubber filled with different carbon blacks. J Appl Polym Sci n/a-n/a

105. Agnelli S, Ramorino G, Passera S, Karger-Kocsis J, Ricco T (2012) Fracture resistance of rubbers with MWCNT, organoclay, silica and carbon black fillers as assessed by the J-integral: Effects of rubber type and filler concentration. Express Polym Lett 6:581-587

106. Dong B, Liu C, Lu Y, Wu Y (2015) Synergistic effects of carbon nanotubes and carbon black on the fracture and fatigue resistance of natural rubber composites. J Appl Polym Sci 132:n/a-n/a

107. Zhou X, Wang L, Cao X, Yin Q, Weng G (2019) Crack resistance improvement of rubber blend by a filler network of graphene. J Appl Polym Sci 136:47278

108. Rooj S, Das A, Morozov IA, Stöckelhuber KW, Stocek R, Heinrich G (2013) Influence of "expanded clay" on the microstructure and fatigue crack growth behavior of carbon black filled NR composites. Compos Sci Technol 76:61-68

109. Knauss WG (1973) On the Steady Propagation of a Crack in a Viscoelastic Sheet: Experiments and Analysis. In: Kausch HH, Hassell JA, Jaffee RI (eds) Deformation and Fracture of High Polymers. Springer US, Boston, MA, pp 501-541

110. Knauss WG (2015) A review of fracture in viscoelastic materials. Int J Fract 196:99-

146

111. Christensen RM (2003) Theory of viscoelasticity, 2nd ed. Dover Publications, Mineola,

N.Y

112. Christensen RM, Wu EM (1981) A theory of crack growth in viscoelastic materials. Eng Fract Mech 14:215-225

113. De Gennes PG (1996) Soft Adhesives. Langmuir 12:4497-4500

114. De Gennes PG (1988) Fracture d'un adhésif faiblement réticulé. Comptes Rendus Académie Sci Sér 2 Mécanique Phys Chim Sci Univers Sci Terre 307:1949-1953

115. Hui C, Xu D, Kramer EJ (1992) A fracture model for a weak interface in a viscoelastic material (small scale yielding analysis). J Appl Phys 72:3294-3304

116. Persson BNJ, Albohr O, Heinrich G, Ueba H (2005) Crack propagation in rubber-like materials. J Phys Condens Matter 17:R1071-R1142

117. Persson BNJ, Brener EA (2005) Crack propagation in viscoelastic solids. Phys Rev E 71:036123

118. Long R, Hui C-Y (2016) Fracture toughness of hydrogels: measurement and interpretation. Soft Matter 12:8069-8086

119. Qi Y, Caillard J, Long R (2018) Fracture toughness of soft materials with rate-independent hysteresis. J Mech Phys Solids 118:341-364

120. Zhang T, Lin S, Yuk H, Zhao X (2015) Predicting fracture energies and crack-tip fields of soft tough materials. Extreme Mech Lett 4:1-8

121. Anderson TL (2005) Fracture Mechanics: Fundamentals and Applications, Third Edition, 3rd ed. CRC Press

122. Maugin GA (1993) Material inhomogeneities in elasticity, 1. ed. Chapman \& Hall, Lon- 
123. Horst T, Heinrich G, Schneider M, Schulze A, Rennert M (2013) Linking Mesoscopic and Macroscopic Aspects of Crack Propagation in Elastomers. In: Grellmann W, Heinrich G, Kaliske M, Klüppel M, Schneider K, Vilgis T (eds) Fracture Mechanics and Statistical Mechanics of Reinforced Elastomeric Blends. Springer Berlin Heidelberg, Berlin, Heidelberg, pp 129-165

124. Gent AN (1996) Adhesion and Strength of Viscoelastic Solids. Is There a Relationship between Adhesion and Bulk Properties? †. Langmuir 12:4492-4496

125. Gent AN, Lai S-M (1994) Interfacial bonding, energy dissipation, and adhesion. J Polym Sci Part B Polym Phys 32:1543-1555

126. Creton C, Ciccotti M (2016) Fracture and adhesion of soft materials: a review. Rep Prog Phys 79:046601

127. Haupt P (2002) Continuum Mechanics and Theory of Materials. Springer Berlin Heidelberg, Berlin, Heidelberg

128. Roucou D (2020) Caractérisation et modélisation du comportement à la déchirure de matériaux élastomères endommagés par chargement multiaxiaux. Ecole Centrale de Lille

129. Saulnier F, Ondarçuhu T, Aradian A, Raphaël E (2004) Adhesion between a Viscoelastic Material and a Solid Surface. Macromolecules 37:1067-1075

130. Klüppel M (2009) Evaluation of viscoelastic master curves of filled elastomers and applications to fracture mechanics. J Phys Condens Matter 21:035104

131. Wunde M, Plagge J, Klüppel M (2019) The role of stress softening in crack propagation of filler reinforced elastomers as evaluated by the J-Integral. Eng Fract Mech 214:520-533

132. Klüppel M, Wunde M (2020) Phase morphology and frature mechanics of rubber blend, book chapter In : Fatigue crack growth in rubber materials; experiments and modelling, Heinrich G, Stocek R (eds). Springer

133. Wang S, Panyukov S, Rubinstein M, Craig SL (2019) Quantitative Adjustment to the Molecular Energy Parameter in the Lake-Thomas Theory of Polymer Fracture Energy. Macromolecules 52:2772-2777 